\title{
Prevalence and Predictors of Frailty in Childhood \\ Cancer Survivors and Siblings: A Report From the Childhood Cancer Survivor Study
}

\author{
Samah Hayek, DrPH${ }^{1}$; Todd M. Gibson, $\mathrm{PhD}^{1}$; Wendy M. Leisenring, $\mathrm{ScD}^{2}$; Jennifer L. Guida, $\mathrm{PhD}^{3}$; Maria Monica Gramatges, $\mathrm{MD}, \mathrm{PhD}^{4}$; \\ Philip J. Lupo, PhD, MPH${ }^{4}$; Rebecca M. Howell, PhD ${ }^{5}$; Kevin C. Oeffinger, MD ${ }^{6}$; Smita Bhatia, MD, MPH ${ }^{7}$; Kim Edelstein, PhD \\ Melissa M. Hudson, MD${ }^{1}$; Leslie L. Robison, $\mathrm{PhD}^{1}$; Paul C. Nathan, MD, MSc ${ }^{9}$; Yutaka Yasui, $\mathrm{PhD}^{1}$; Kevin R. Krull, $\mathrm{PhD}^{1}$; \\ Gregory T. Armstrong, MD, MSCE${ }^{1}$; and Kirsten K. Ness, MPH, PhD ${ }^{1}$
}

PURPOSE To estimate the prevalence of frailty among childhood cancer survivors and to determine the direct and indirect effects of treatment exposures, lifestyle factors, and severe, disabling, and life-threatening chronic condition on frailty.

METHODS Childhood cancer survivors ( $\geq 5$ years since diagnosis), treated between 1970 and 1999 when $<21$ years old ( $n=10,899$; mean age, $37.6 \pm 9.4$ years; $48 \%$ male, $86 \%$ white) and siblings were included ( $n=2,097$; mean age, $42.9 \pm 9.4$ years). Frailty was defined as $\geq 3$ of the following: low lean mass, exhaustion, low energy expenditure, walking limitations, and weakness. Generalized linear models were used to evaluate direct and indirect associations between frailty and treatment exposures, sociodemographic characteristics, lifestyle factors, and chronic condition.

RESULTS The overall prevalence of frailty among survivors was 3 times higher compared with siblings (6.4\%; $95 \% \mathrm{Cl}, 4.1 \%$ to $8.7 \%$; $v 2.2 \%$; $95 \% \mathrm{Cl}, 1.2 \%$ to $3.2 \%)$. Survivors of CNS tumors $(9.5 \%$; $95 \% \mathrm{Cl}, 5.2 \%$ to $13.8 \%$ ) and bone tumors (8.1\%; $95 \% \mathrm{Cl}, 5.1 \%$ to $11.1 \%$ ) had the highest prevalence of frailty. Survivors exposed to cranial radiation, pelvic radiation $\geq 34$ Gy, abdominal radiation $>40 \mathrm{~Gy}$, cisplatin $\geq 600 \mathrm{mg} / \mathrm{m}^{2}$, amputation, or lung surgery had increased risk for frailty. These associations were partially but not completely attenuated when sociodemographic characteristics, lifestyle factors, and chronic conditions were added to multivariable models. Cranial radiation (prevalence ratio [PR], 1.47; $95 \% \mathrm{Cl}, 1.20$ to 1.76), pelvic radiation $\geq 34$ Gy (PR, 1.46; $95 \% \mathrm{Cl}, 1.01$ to 2.11 ), and lung surgery (PR, 1.75; $95 \% \mathrm{Cl}, 1.28$ to 2.38) remained significant after sociodemographic, lifestyle, and chronic conditions were accounted for.

CONCLUSION Childhood cancer survivors reported a higher prevalence of frailty compared with siblings. Radiation and lung surgery exposures were associated with increased risk for frailty. Interventions to prevent, delay onset, or remediate chronic disease and/or promote healthy lifestyle are needed to decrease the prevalence of frailty and preserve function in this at-risk population.

J Clin Oncol 38:232-247. @ 2019 by American Society of Clinical Oncology

\section{INTRODUCTION}

Because of improvements in therapy, 5 -year survival for children diagnosed with cancer has surpassed $85 \%{ }^{1}$ Nevertheless, childhood cancer survivors continue to report problems with health status and experience chronic conditions at high frequencies, accumulating on average 4.7 ( $95 \% \mathrm{Cl}, 4.6$ to 4.9$)$ severe, disabling, or life-threatening chronic conditions by age 50 years, ${ }^{2}$ compared with 2.3 (95\% Cl, 1.9 to 2.7) among peers. ${ }^{2}$

Consequently, current research and clinical care are focused on improving long-term health among survivors. To accomplish this goal, intermediate markers of health need to be identified. These markers may signal early disease and provide opportunities for intervention. Recent studies have described frailty, a loss of physiologic reserve typically seen in older adults, as a potential marker in adult survivors of childhood cancer. ${ }^{3}$ In the general population, frailty increases with age and is predictive of chronic disease onset and mortality. ${ }^{4}$

Our previous single-institution study, using a clinically assessed population, provided important preliminary information about the prevalence of and risk factors for frailty phenotype. ${ }^{3}$ However, replication of these findings in the Childhood Cancer Survivor Study (CCSS), a large multi-institutional cohort that has been followed for $>25$ years, offers the opportunity to validate and further explore associations between treatment and frailty and test the hypothesis that chronic disease and/or health behaviors partially mediate the association between treatment and frailty in survivors. Thus, the aims of these analyses were to enumerate the prevalence of frailty in a large, geographically diverse population of survivors, compare

\section{ASCO}


rates among survivors to siblings, identify treatment-related risk factors for frailty, and examine direct and indirect effects of treatment exposures and health behaviors on frailty among survivors (Appendix Fig A1, online only).

\section{METHODS}

\section{Study Population}

The CCSS is a retrospective cohort of childhood cancer survivors and their siblings. Survivors were diagnosed when $<21$ years of age, treated at one of 31 institutions in North America between January 1, 1970 and December 31, 1999 , and survived $\geq 5$ years after diagnosis, regardless of recurrence status. The cohort has been followed since 1995; current participants are a median 30 years from diagnosis. Diagnoses included leukemia, CNS tumor, Hodgkin lymphoma, non-Hodgkin lymphoma, neuroblastoma, Wilms tumor, soft tissue sarcoma, or bone tumor. At cohort entry, survivors identified a sibling nearest to them in age. A random sample of siblings were contacted to participate. Details of study methodology and data collection have been described. ${ }^{5-7}$ Survivors and siblings provided informed consent, and institutional review boards at all sites approved the study. Participants completed a baseline survey that included sociodemographics, lifestyle factors, medical history, and chronic health conditions. A proxy (parent, spouse, or next of kin) completed the baseline survey for survivors who died $\geq 5$ years after diagnosis or who were $<18$ years old. Study documents are available at http://ccss.stjude.org. ${ }^{8}$ To be eligible for these analyses, survivors and siblings were alive, $\geq 18$ years old, and completed a follow-up questionnaire between 2014 and 2016 (follow-up 5). Data from all available questionnaires were used.

\section{Outcomes}

The primary outcome was frailty, categorized using modified Fried frailty criteria ${ }^{9}$ : (1) low lean muscle mass: body mass index (BMI) of $<18.5 \mathrm{~kg} / \mathrm{m}^{2}$ or unintentional weight loss of $\geq 10$ pounds in the past year; (2) self-reported exhaustion: score of $\leq 40$ on the Vitality subscale of the Medical Outcomes Survey Short Form-36 ${ }^{10}$; (3) low energy expenditure: $<383 \mathrm{kcal} / \mathrm{wk}$ males and $<270 \mathrm{kcal} / \mathrm{wk}$ females from conversion of frequency and duration of low, moderate, and vigorous activities ${ }^{11,12}$; (4) walking limitations: "limited for more than 3 months" in response to "Over the last 2 years, how long has your health limited you in walking uphill or climbing a few flights of stairs?" or "Over the last 2 years, how long has your health limited you in walking one block?"; and (5) weakness: "yes and the condition is still present" to "Have you ever been told by a doctor or other health care professional that you have, or have had, weakness or inability to move your arms?" Participants endorsing at least 2 of 5 criteria were considered prefrail, and those endorsing $\geq 3$ were considered frail.

\section{Other Variables}

Lifestyle factors. Smoking, alcohol use, sedentary behavior, and obesity characterized patterns of health behavior and were classified as never, former, or current engagement. Smokers reported smoking $\geq 100$ cigarettes in their lifetime and smoking in the past month. Risky/heavy drinkers were males who reported $\geq 1$ incident of $\geq 5$ drinks in a single day, or an average of 14 drinks/wk, or females who reported $\geq 1$ incident of $\geq 4$ drinks in a single day or an average of 7 drinks/wk in the year before the questionnaire. ${ }^{13}$ Persons who responded no to "During the past month, did you participate in any physical activities or exercise such as running, aerobic, golf, gardening, bicycling, swimming, wheelchair basketball, or walking for exercise?" were classified as sedentary. ${ }^{14,15}$ Obesity was defined as a BMI of $\geq 30 \mathrm{~kg} / \mathrm{m}^{2}$. ${ }^{13,16}$

Chronic health conditions. Chronic conditions were graded according to the National Cancer Institute Common Terminology Criteria for Adverse Events version 4.03, where $0=$ none; 1 = mild or asymptomatic conditions; 2 = moderate conditions; 3 = severe, medically significant, or disabling conditions; and $4=$ life-threatening conditions. ${ }^{17}$ For these analyses, chronic conditions grade 3-4, overall and by individual organ system, were evaluated ${ }^{18}$ as binary indicators and as continuous variables (time in years the condition was present).

Treatment information. Treatment exposures within 5 years of cancer diagnosis were examined using continuous dose exposures and then, on the basis of preliminary analysis, categorized as: alkylating agents (yes/no), anthracyclines (yes/no), cisplatin (none, $<600 \mathrm{mg} / \mathrm{m}^{2}, \geq 600 \mathrm{mg} / \mathrm{m}^{2}$ ), carboplatin (none, $<2,500 \mathrm{mg} / \mathrm{m}^{2}, \geq 2,500 \mathrm{mg} / \mathrm{m}^{2}$ ), 6-mercaptopurine (yes/no), 6-thioguanine (yes/no), methotrexate (yes/no), vinca alkaloids (yes/no), cranial radiation (yes/no), chest radiation (yes/no), abdominal radiation (none, $<34 \mathrm{~Gy}, \geq 34 \mathrm{~Gy}$ ), pelvic radiation (none, $<20$ Gy, 20-40 Gy, > 40 Gy), other region radiation (yes/ no), amputation (yes/no), spleen removal (yes/no), and lung surgery (yes/no). Radiation dose was determined by summing prescribed doses to all overlapping fields within each respective region. Education status, employment, and annual household income data were captured from the most recent questionnaire.

\section{Statistical Analysis}

Descriptive statistics characterized the study population. Two-sample $t$ tests and $\chi^{2}$ tests compared participants with nonparticipants. Generalized linear models compared sexstratified percentages of prefrailty, frailty, and frailty components by age group and included an error term for treating institution, and, when survivors were compared with siblings in age- and sex-adjusted models, an error term for family membership.

Generalized linear models, ${ }^{19,20}$ including an error term for treating institution, examined the direct and indirect effects 
TABLE 1. Demographic and Treatment Characteristics of Survivors of Childhood Cancer and Siblings

\section{Characteristic}

Survivors of Childhood Cancer

Age at baseline questionnaire, years

Mean (SD)
Range

Age at diagnosis, years

\begin{tabular}{ll}
\hline $0-4$ & $4,095(40.2)$ \\
\hline $5-9$ & $2,430(23.7)$ \\
\hline $10-14$ & $2,459(20.6)$ \\
\hline$\geq 15$ & $1,915(15.6)$ \\
\hline
\end{tabular}

Sex

Female

Male

( $N=10,899)$

$\begin{array}{cc}24.3(8.9) & 24.5(8.4) \\ 5-56 & 5-50\end{array}$

Siblings

( $N=2,097$ )

Race/ethnicity

Non-Hispanic white

Non-Hispanic black

Hispanic

Other*

Age at assessment, years

Mean (SD)

18-29

30-39

40-49

$\geq 50$

Not specified

Education

Less than high school

High school graduate

College graduate

Post graduate

Not specified

Household income, USD

$<\$ 40,000$

$\geq \$ 40,000$

Not reported

Smoking status

Never

Current

Former

Not reported
$37.6(9.4)$

5,709 (52.3)

$5,190(47.7)$

9,401 (85.7)

452 (4.3)

$661(6.3)$

385 (3.7)

$37.6(9.4)$
$2,120(24.7)$
$4,206(38.3)$
$3,160(25.6)$
$1,413(11.4)$

$8,191(75.0)$

$1,810(16.2)$

$835(8.8)$

63
408 (4.0)

$1,970(18.1)$

$6,737(62.6)$

1,677 (15.3)

107

3,156 (33.2)

6,537 (66.8)

1,206

7,484 (69.4)

$1,904(17.8)$

1,473 (12.8)

38
$<.001$

$1,214(57.9)$

$883(42.1)$

$1,877(89.5)$

$27(1.3)$

69 (3.3)

124 (5.9)

$42.9(9.4)$
$161(7.7)$
$610(29.1)$
$725(34.6)$
$601(28.6)$

$<.001$

$<.001$

$<.001$

$1,870(89.4)$

$94(4.5)$

$129(6.1)$

4

$<.001$

$51(2.4)$

293 (14.0)

$1,283(61.4)$

464 (22.2)

6

$<.001$

383 (19.7)

$1,558(80.3)$

156

(continued on following page)

$1,239(59.1)$

405 (19.3)

451 (21.6)

2 
TABLE 1. Demographic and Treatment Characteristics of Survivors of Childhood Cancer and Siblings (continued)

\section{Characteristic}

Heavy drinking $\ddagger$

Never

Current

Former

Not reported

Sedentary behavior\$

Never

Current

Former

Obesity (BMI $\geq 30 \mathrm{~kg} / \mathrm{m}^{2}$ )

Never

Current

Former

Not reported

Health insurance

$$
\text { No }
$$

Yesll

Not reported

Grade 3-4 chronic condition

Duration, years

Mean (SD)

Median

Range

Endocrine condition grade 3-4

Duration, years

Mean (SD)

Median

Range

Respiratory condition grade 3-4

Duration, years

\begin{tabular}{ll}
\hline Mean (SD) & 20.6 \\
\hline Median & 7.8 \\
\hline Range & 591 \\
\hline Cardiac condition grade 3-4 \\
\hline Duration, years
\end{tabular}

Mean (SD)

Median

Range

Renal condition grade 3-4

Duration, years

Mean (SD)

Median

Range

\section{Survivors of Childhood Cancer}

$(\mathrm{N}=10,899)$

8,747 (84.9)

$367(3.5)$

1,170 (11.6)

615

7,214 (68.3)

2,135 (19.2)

$1,550(12.5)$

7,840 (74.7)

2,572 (22.8)

301 (2.5)

186

979 (9.2)

9,860 (90.8)

60

3,409 (28.8)

17.1 (11.9)

16

0-57

802 (6.6)

19.8 (9.7)

19.4

1.9-45.9

$64(0.5)$

20.6 (8.1)

19.3

7.8-43.9

$591(5.1)$

$18.1(9.1)$

16.9

2.8-43.9

$85(0.7)$

$21.3(9.1)$

20.9

6.8-42.8

(continued on following page)

Siblings

( $N=2,097)$

1,676 (80.7)

104 (5.0)

296 (14.3)

21

1,385 (66.0)

$<.001$

253 (12.1)

459 (21.9)

$1,416(67.5)$

593 (28.5)

83 (3.9)

5

138 (6.6)

1,949 (93.4)

10

$195(9.3)$

$<.001$

$<.001$

$<.001$ 
TABLE 1. Demographic and Treatment Characteristics of Survivors of Childhood Cancer and Siblings (continued)

\begin{tabular}{|c|c|c|c|}
\hline Characteristic & $\begin{array}{l}\text { Survivors of Childhood Cancer } \\
\qquad(N=10,899)\end{array}$ & $\begin{array}{c}\text { Siblings } \\
(N=2,097)\end{array}$ & $P$ \\
\hline SMN grade $3-4$ & $500(4.2)$ & 27 (1.3) & $<.001$ \\
\hline \multicolumn{4}{|l|}{ Duration, years } \\
\hline Mean (SD) & $15.3(6.9)$ & $13.4(7.9)$ & .64 \\
\hline Median & 13.9 & 13.4 & \\
\hline \multicolumn{4}{|l|}{ Duration, years } \\
\hline Mean (SD) & $25.4(8.7)$ & $24.7(10.1)$ & .72 \\
\hline Median & 25.9 & 23.3 & \\
\hline Range & $3.8-45.7$ & 7.3-42.2 & \\
\hline \multicolumn{4}{|l|}{ Duration, years } \\
\hline Median & 29.3 & 13.8 & \\
\hline Range & $4.7-46.8$ & 7.8-34.4 & \\
\hline All other grade 3-4 conditions & $1,354(11.4)$ & $83(4.0)$ & $<.001$ \\
\hline \multicolumn{4}{|l|}{ Duration, years } \\
\hline Mean (SD) & $22.9(9.4)$ & $30.7(14.0)$ & $<.001$ \\
\hline Median & 22.7 & 28.9 & \\
\hline Range & $4.1-46.5$ & $7.1-66.5$ & \\
\hline
\end{tabular}

NOTE. Data presented as No. (\%) unless otherwise noted. Sampling weights have been applied for all percentages.

Abbreviations: BMI, body mass index; SD, standard deviation; SMN, second malignant neoplasm; USD, United States dollars.

${ }^{*}$ Category other: Asian, not specified, or other.

†Employed: full time, part time, or caring for home/family.

¥Heavy drinking: $\geq 5$ drinks per day or 14 drinks per week for men; $\geq 4$ drinks per day or 7 drinks per week for women.

§Sedentary behavior: persons who responded no to the question: "During the past month, did you participate in any physical activities such as running, aerobic, golf, gardening, bicycling, swimming, wheelchair basketball, or walking for exercise?"

IIYes: includes participants with Canadian health insurance.

TGrade 3-4 chronic condition: having at least one chronic condition grade 3-4.

of treatment exposures on frailty, treating lifestyle, and grade 3-4 of chronic conditions as mediators. Using the strategy described by Baron and Kenny, ${ }^{21} 3$ stages of regression models were constructed. The first stage regressed chronic conditions and lifestyle on treatment exposures (Appendix Tables A1 and A2, online only), the second regressed frailty on treatment exposures, and the third regressed frailty on treatment, chronic conditions, and lifestyle. We also investigated the effects of treatment era alone on frailty and then in a model that included treatment. Adding treatment to the model completely attenuated the effects of era; thus, we did not include era in our final model. Change in prevalence rate ratios, model $\chi^{2}$ statistics, and Akaike information criteria were examined to evaluate relative fit of each model. ${ }^{22,23}$ In additional analyses, the frailty phenotype was evaluated as an ordinal outcome using multinomial logistic regression.

For all the analyses, survey weights were included to account for intentional undersampling of acute lymphoblastic leukemia survivors treated between 1987 and 1999. We used a false discovery rate $<10 \%$ to account for type I error related to multiple comparison. ${ }^{24}$ SAS version 9.4 (Cary, NC) was used to conduct all statistical analyses (all 2-sided).

\section{RESULTS}

\section{Participant Characteristics}

Among 20,834 cohort members, 10,899 were $\geq 18$ years old and completed the most recent follow-up questionnaire characterizing frailty. There were 6,355 nonresponders, 2,021 active refusals, 103 lost to follow-up, 373 with missing data, and 1,083 lost to follow-up at the time of the survey (Appendix Fig A2, online only). Compared with nonparticipants, participants were more likely to be older at diagnosis, female, non-Hispanic white, and treated for CNS tumors (Appendix Table A3, online only).

Among 2,146 siblings, 2,097 were $\geq 18$ years old and completed the most recent follow-up questionnaire (Appendix 
TABLE 2. Associations Between Treatment Exposures and Frailty Among Survivors

Frailty $(n=681)^{*}$

Prefrailty $(n=1,953) \dagger$

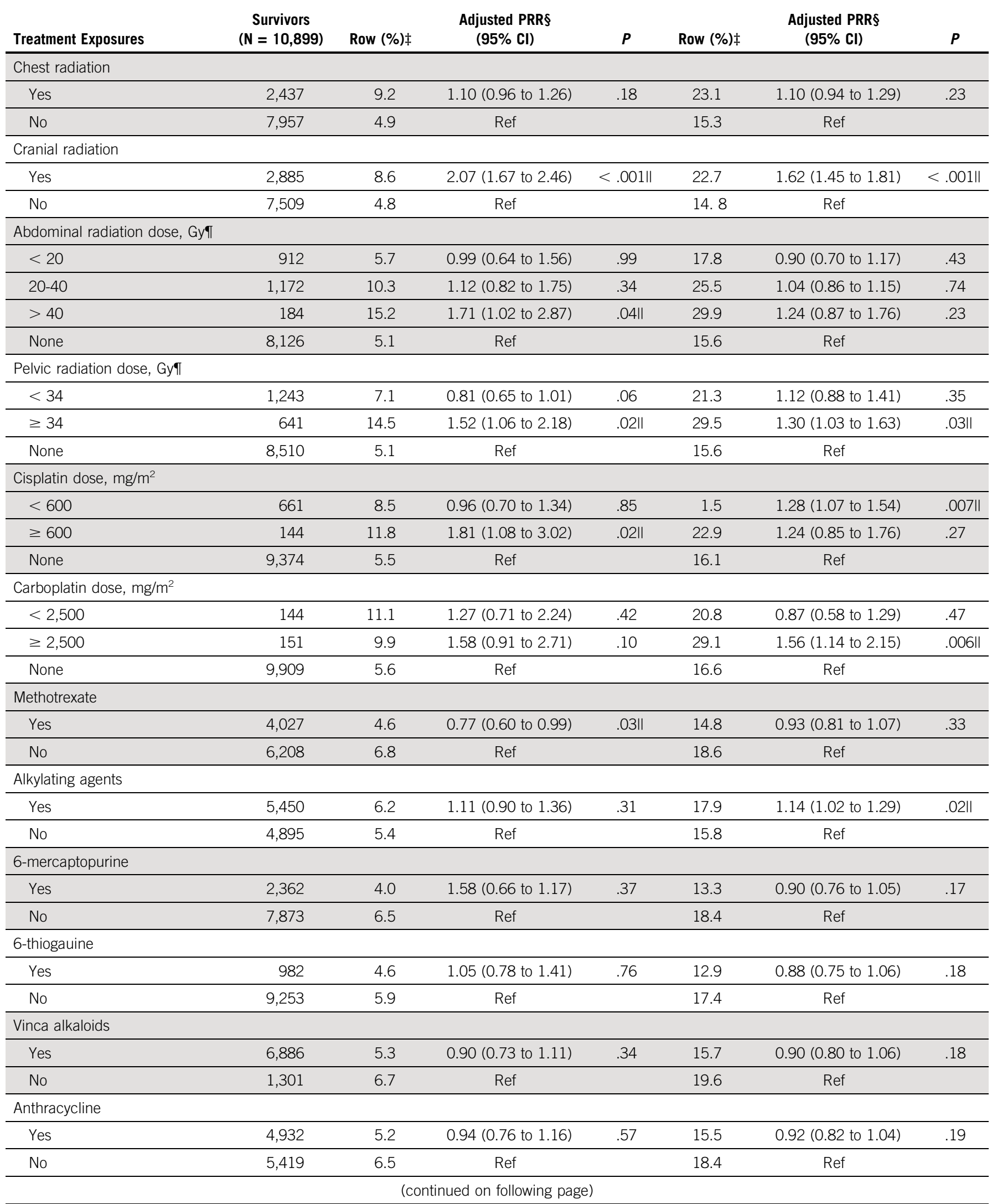


TABLE 2. Associations Between Treatment Exposures and Frailty Among Survivors (continued)

\begin{tabular}{|c|c|c|c|c|c|c|c|}
\hline \multirow[b]{2}{*}{ Treatment Exposures } & \multirow[b]{2}{*}{$\begin{array}{c}\text { Survivors } \\
(\mathrm{N}=10,899)\end{array}$} & \multicolumn{3}{|c|}{ Frailty $(n=681)^{*}$} & \multicolumn{3}{|c|}{ Prefrailty $(n=1,953) \dagger$} \\
\hline & & Row (\%)‡ & $\begin{array}{l}\text { Adjusted PRR§ } \\
\text { (95\% Cl) }\end{array}$ & $P$ & Row (\%)‡ & $\begin{array}{l}\text { Adjusted PRR§ } \\
\quad(95 \% \mathrm{Cl})\end{array}$ & $P$ \\
\hline Yes & 441 & 11.3 & 1.86 (1.30 to 2.67$)$ & $<.001 \|$ & 28.6 & 1.54 (1.11 to 1.39$)$ & $<.001 \|$ \\
\hline No & 10,374 & 5.6 & Ref & & 16.5 & Ref & \\
\hline No & 10,292 & 5.5 & Ref & & 16.3 & Ref & \\
\hline \multicolumn{8}{|l|}{ Spleen removal } \\
\hline Yes & 753 & 8.0 & 0.87 (0.62 to 1.24$)$ & .49 & 22.8 & 1.14 (0.93 to 1.39$)$ & .22 \\
\hline No & 9,970 & 5.7 & Ref & & 16.6 & Ref & \\
\hline
\end{tabular}

Abbreviations: PRR, prevalence rate ratio; Ref, reference.

*Frailty $\geq 3$ components.

$\dagger$ Prefrailty $\geq 2$ components.

$\ddagger$ Weighted row percentages are presented.

$\S$ The model was adjusted for sex, race, age at diagnosis, and age at assessment.

IIIndicates estimates with a false discovery rate $<10 \%$.

IRadiation dose: maximum tumor dose was determined by summing the prescribed dose to all overlapping fields within each respective region.

Fig A3, online only). Siblings were more likely than survivors to be female, non-Hispanic white, $\geq 50$ years old at the last questionnaire, and employed, and had higher educational attainment and annual household incomes (Table 1). Siblings were also more likely than survivors to be current smokers, be heavy drinkers, report a sedentary lifestyle, and be classified as obese. Survivors reported a higher prevalence of any grade 3-4 chronic conditions than siblings.

\section{Prevalence}

The prevalence of frailty was $6.4 \%(95 \% \mathrm{Cl}, 4.1 \%$ to $8.7 \%)$ among survivors, and $2.2 \%(95 \% \mathrm{Cl}, 1.2 \%$ to $3.2 \%$ ) among siblings (Appendix Fig A4, online only). The prevalence of prefrailty and frailty were higher among females than males for both survivors and siblings in most age groups (Appendix Table A4, online only). Among survivors, walking limitations ( $85.0 \%$; $95 \% \mathrm{Cl}, 82.2 \%$ to $87.7 \%$ ), low energy expenditure $(82.9 \%$; $95 \% \mathrm{Cl}, 79.7 \%$ to $86.1 \%)$, and selfreported exhaustion $(80.5 \%$; $95 \% \mathrm{Cl}, 77.8 \%$ to $83.0 \%$ ) were the three frailty components with the highest prevalence (Appendix Fig A5, online only). Appendix Figure A6 (online only) shows age-adjusted prevalence of prefrailty and frailty by diagnosis. Survivors with CNS tumors had the highest prevalence of frailty and prefrailty $(9.5 \%$ and $26.1 \%$ respectively), followed by those with bone tumors ( $8.1 \%$ and $22.5 \%$, respectively) and Hodgkin lymphoma (7.5\% and $19.5 \%$, respectively).

\section{Treatment Exposure and Frailty}

Models adjusted for sex, race/ethnicity, age at diagnosis, and age at assessment showed that cranial radiation, pelvic radiation $\geq 34 \mathrm{~Gy}$, abdominal radiation $>40 \mathrm{~Gy}$, cisplatin $\geq 600 \mathrm{mg} / \mathrm{m}^{2}$, amputation, or lung surgery increased risk for frailty. Exposure to cranial radiation, pelvic radiation $\geq 34$ Gy, cisplatin $<600 \mathrm{mg} / \mathrm{m}^{2}$, carboplatin $\geq 2,500 \mathrm{mg} / \mathrm{m}^{2}$, alkylating agents, amputation, or lung surgery were associated with prefrailty (Table 2 ).

\section{Demographics, Lifestyle, and Frailty}

Demographic and lifestyle variables associated with frailty and prefrailty included female sex, age at diagnosis, nonHispanic black or Hispanic race/ethnicity, sedentary lifestyle, smoking, and obesity (Table 3 ).

\section{Chronic Conditions and Frailty}

Table 4 and Appendix Table A5 (online only) show associations between prevalent grade 3-4 chronic conditions and duration of chronic conditions and frailty and prefrailty among survivors. Compared with those without organ system-specific chronic conditions, frailty prevalence was higher among those with respiratory, neurologic, musculoskeletal, cardiac, and endocrine conditions. Respiratory, second malignant neoplasm (SMN), cardiac, neurologic, and musculoskeletal grade 3-4 chronic conditions were associated with prefrailty. The prevalence of frailty and prefrailty was higher among survivors whose chronic conditions were of longer duration.

\section{Treatment Exposure, Chronic Conditions, Lifestyle, and Frailty}

Table 5, Figures $1 \mathrm{~A}$ and $1 \mathrm{~B}$, and Appendix Tables A6 and A7 (online only) show the mediating effects of chronic health conditions and lifestyle on the association of treatment exposures with frailty and prefrailty and the relative fit of each model. Adding grade 3-4 organ-specific chronic conditions to the model attenuated, but did not completely 
TABLE 3. Associations Between Sociodemographic Characteristics, Lifestyle, and Frailty Among Survivors

\begin{tabular}{|c|c|c|c|c|c|c|c|}
\hline \multirow[b]{2}{*}{ Factors } & \multirow{2}{*}{$\begin{array}{c}\text { Survivors } \\
(\mathrm{N}=10,899)\end{array}$} & \multicolumn{3}{|c|}{ Frailty $(n=681)^{*}$} & \multicolumn{3}{|c|}{ Prefrailty $(n=1,953) \dagger$} \\
\hline & & Row (\%)‡ & Adjusted PRR (95\% CI) & $P$ & Row (\%) $\ddagger$ & Adjusted PRR (95\% Cl) & $P$ \\
\hline \multicolumn{8}{|l|}{ Age at diagnosis, years } \\
\hline $5-9$ & 2,459 & 5.9 & 0.84 (0.66 to 1.07 & .68 & 16.8 & 0.86 (0.75 to 1.00$)$ & $.06 \S$ \\
\hline $10-14$ & 2,430 & 7.3 & 0.94 (0.75 to 1.18$)$ & .61 & 20.5 & 1.02 (0.88 to 1.17 ) & .77 \\
\hline \multicolumn{8}{|l|}{ Sex } \\
\hline Female & 5,709 & 6.8 & 1.30 (1.12 to 1.52$)$ & $<.001 \S$ & 19.7 & 1.32 (1.21 to 1.44$)$ & $<.001 \S$ \\
\hline Male & 5,190 & 4.7 & Ref & & 14.2 & Ref & \\
\hline \multicolumn{8}{|l|}{ Race/ethnicity } \\
\hline Non-Hispanic white & 9,401 & 5.4 & Ref & & 16.4 & Ref & \\
\hline \multicolumn{8}{|c|}{ Age at assessment, years } \\
\hline $18-29$ & 2,120 & 3.7 & Ref & & 12.8 & Ref & \\
\hline 30-39 & 4,206 & 5.5 & 1.18 (0.92 to 1.50$)$ & .19 & 16.7 & $1.10(0.96$ to 1.24$)$ & .18 \\
\hline $40-49$ & 3,160 & 7.0 & 1.23 (0.93 to 1.21$)$ & .12 & 19.4 & 1.10 (0.94 to 1.27$)$ & .26 \\
\hline$\geq 50$ & 1,413 & 8.9 & 1.34 (0.90 to 1.85$)$ & .08 & 22.3 & 1.11 (0.94 to 1.35$)$ & .28 \\
\hline \multicolumn{8}{|l|}{ Smoking status\|l } \\
\hline Current & 1,904 & 7.9 & 1.29 (1.08 to 1.54$)$ & $.005 \S$ & 22.2 & 1.31 (1.18 to 1.46$)$ & $<.001 \S$ \\
\hline Former & 1,473 & 5.8 & 0.96 (0.76 to 1.21$)$ & .74 & 16.7 & 0.99 (0.87 to 1.14$)$ & .92 \\
\hline Current & 2,572 & 8.7 & 1.42 (1.21 to 1.67$)$ & $<.001 \S$ & 24.2 & 1.41 (1.28 to 1.55$)$ & $<.001 \S$ \\
\hline Former & 301 & 9.6 & 1.32 (0.90 to 1.93 ) & .15 & 26.3 & 1.34 (1.06 to 1.70$)$ & $.01 \S$ \\
\hline Never & 7,840 & 4.8 & Ref & & 14.6 & Ref & \\
\hline
\end{tabular}

Abbreviations: BMI, body mass index; PRR, prevalence rate ratio; Ref, reference.

*Frailty $\geq 3$ components.

†Prefrailty $\geq 2$ components.

$\ddagger$ Weighted row percentages.

\$Indicates estimates with a false discovery rate $<10 \%$.

IISmoking status was defined as those who reported $\geq 100$ cigarettes in their lifetime and smoking in the past month; 35 participants did not report their smoking status.

TSedentary behavior: persons who responded no to the question: "During the past month, did you participate in any physical activities such as running, aerobic, golf, gardening, bicycling, swimming, wheelchair basketball, or walking for exercise?"

explain, associations between cranial radiation, pelvic radiation $\geq 34$ Gy, lung surgery, and frailty. However, associations between cisplatin dose $\geq 600 \mathrm{mg} / \mathrm{m}^{2}$, abdominal radiation dose $>40 \mathrm{~Gy}$, amputation, and frailty became null when organ-specific grade 3-4 chronic conditions were added to the model. When lifestyle factors were included in the model with treatment and grade 3-4 organ- specific chronic health conditions, the association between cranial radiation and frailty was further attenuated but remained significant (Table 5).

Adding grade 3-4 organ-specific chronic conditions to the model attenuated associations between cranial radiation, carboplatin dose $\geq 2,500 \mathrm{mg} / \mathrm{m}^{2}$, cisplatin dose $<600 \mathrm{mg} / \mathrm{m}^{2}$, 
TABLE 4. Associations Between Grade 3-4 Chronic Health Conditions and Frailty Among Survivors

Frailty $(n=681)^{*}$

Prefrailty $(n=1,953) \dagger$

\begin{tabular}{|c|c|c|c|c|c|c|c|}
\hline Grade 3-4 Chronic Conditions & $\begin{array}{c}\text { Survivors } \\
(\mathrm{N}=10,899)\end{array}$ & Row (\%)‡ & Adjusted PRR (95\% CI)§ & $P$ & Row (\%) $\ddagger$ & Adjusted PRR $(95 \% \mathrm{CI}) \S$ & $P$ \\
\hline \multicolumn{8}{|l|}{ Any chronic conditionll } \\
\hline No & 7,490 & 3.6 & Ref & & 12.5 & Ref & \\
\hline \multicolumn{8}{|l|}{ Cardiac } \\
\hline No & 10,308 & 5.2 & Ref & & 16.1 & Ref & \\
\hline \multicolumn{8}{|l|}{ SMN } \\
\hline Yes & 500 & 12.0 & 1.26 (0.95 to 1.66$)$ & .11 & 28.3 & $1.21(1.02$ to 1.41$)$ & .03 \\
\hline No & 10,399 & 5.6 & Ref & & 16.6 & Ref & \\
\hline \multicolumn{8}{|l|}{ Neurologic } \\
\hline Yes & 596 & 11.7 & 1.75 (1.36 to 2.25$)$ & $<.0019$ & 29.2 & 1.59 (1.39 to 1.82$)$ & $<.0019$ \\
\hline No & 10,303 & 5.5 & Ref & & 16.4 & Ref & \\
\hline \multicolumn{8}{|l|}{ Endocrine } \\
\hline Yes & 802 & 12.1 & 1.61 (1.28 to 2.03 ) & $<.001 \rrbracket$ & 27.5 & 1.31 (1.14 to 1.50$)$ & $<.001 \uparrow$ \\
\hline No & 10,097 & 5.4 & Ref & & 17.0 & Ref & \\
\hline \multicolumn{8}{|l|}{ Respiratory } \\
\hline Yes & 64 & 31.0 & 3.17 (2.03 to 4.94$)$ & $<.001 \rrbracket$ & 46.0 & 1.86 (1.43 to 2.43 ) & $<.001 \uparrow$ \\
\hline No & 10,835 & 5.7 & Ref & & 16.9 & Ref & \\
\hline
\end{tabular}

Abbreviations: PRR, prevalence rate ratio; Ref, reference; SMN, second malignant neoplasm.

*Frailty $\geq 3$ components.

$\dagger$ Prefrailty $\geq 2$ components.

$\ddagger$ Weighted row percentages.

$\S$ The model was adjusted for sex, race, age at diagnosis, and age at assessment.

IIAny chronic condition was conducted in separate model, and the PRR $(95 \% \mathrm{Cl})$ was reported in the table.

IIndicates estimates with a false discovery rate $<10 \%$.

lung surgery, and prefrailty. However, associations between pelvic radiation $\geq 34 \mathrm{~Gy}$, alkylating agents, amputation, and prefrailty became null when organ-specific grade 3-4 chronic conditions were added to the model. When lifestyle factors were included in the model with treatment and grade 3-4 organ-specific chronic conditions, the association between cranial radiation and prefrailty was further attenuated but remained significant (Table 5). Results from multinomial logistic regressions were consistent with our dichotomous outcome findings (Appendix Tables A8-Tables A12, online only).

\section{DISCUSSION}

Using a large longitudinal and geographically diverse cohort, this study further characterizes and provides new data about risk factors for frailty among childhood cancer survivors. Among nearly 11,000 5-year survivors, a mean age of 37.6 ( \pm 9.4 ) years at assessment, the presence of frailty, a phenotype typically seen among older adults, was 3 times higher than among siblings. Our results identify a novel association between lung surgery and frailty, while validating previously reported associations between cranial or 
TABLE 5. Associations Between Treatment Exposures, Grade 3-4 Chronic Conditions, Lifestyle Factors, and Prefrailty or Frailty Among Survivors

Frailty $\left(n=681^{\text {a }}\right.$

Factors

Sex

Female

Race/ethnicity

Non-Hispanic black

Hispanic

Others

Non-Hispanic white

Age at diagnosis, years

\begin{tabular}{|c|c|c|c|c|}
\hline $0-4$ & $0.60(0.45$ to 0.80$)$ & $<.001^{\mathrm{e}}$ & 0.79 (0.67 to 0.94$)$ & $.006^{\mathrm{e}}$ \\
\hline $5-10$ & 0.76 (0.58 to 0.99$)$ & $.04^{\mathrm{e}}$ & 0.87 (0.74 to 1.02$)$ & .09 \\
\hline $10-14$ & 0.97 (0.76 to 1.23$)$ & .80 & 0.99 (0.87 to 1.15$)$ & .98 \\
\hline$\geq 15$ & Ref & & Ref & \\
\hline \multicolumn{5}{|c|}{ Age at assessment, years } \\
\hline $18-29$ & Ref & & Ref & \\
\hline 30-39 & $1.02(0.80$ to 1.31$)$ & .87 & 1.03 (0.90 to 1.17 ) & .74 \\
\hline $40-49$ & $1.06(0.80$ to 1.41$)$ & .72 & 1.03 (0.87 to 1.28 ) & .77 \\
\hline$\geq 50$ & $1.12(0.80$ to 1.61$)$ & .52 & 1.03 (0.83 to 1.28$)$ & .80 \\
\hline \multicolumn{5}{|c|}{ Cranial radiation } \\
\hline Yes & 1.47 (1.20 to 1.76$)$ & $<.001^{\mathrm{e}}$ & 1.25 (1.12 to 1.40$)$ & $<.001^{\mathrm{e}}$ \\
\hline No & Ref & & Ref & \\
\hline
\end{tabular}

Abdominal radiation dose, $\mathrm{Gy}^{\mathrm{f}}$

\begin{tabular}{|c|c|c|c|c|}
\hline$<20$ & $1.32(0.90$ to 2.01$)$ & .19 & $\mathrm{~g}$ & \\
\hline $20-40$ & 1.26 (0.90 to 1.77$)$ & .20 & $\mathrm{~g}$ & \\
\hline$>40$ & 1.46 (0.88 to 2.18$)$ & .14 & $\mathrm{~g}$ & \\
\hline None & Ref & & $\mathrm{g}$ & \\
\hline \multicolumn{5}{|c|}{ Pelvic radiation dose, $\mathrm{Gy}^{f}$} \\
\hline$<34$ & 0.98 (0.67 to 1.45$)$ & .95 & 1.06 (0.85 to 1.33$)$ & .61 \\
\hline$\geq 34$ & 1.46 (1.01 to 2.11$)$ & $.04^{\mathrm{e}}$ & 1.20 (0.95 to 1.50$)$ & .15 \\
\hline None & Ref & & Ref & \\
\hline \multicolumn{5}{|c|}{ Cisplatin dose, $\mathrm{mg} / \mathrm{m}^{2}$} \\
\hline$<600$ & 0.96 (0.70 to 1.32$)$ & .78 & 1.22 (1.02 to 1.47 ) & .03 \\
\hline$\geq 600$ & 1.37 (0.82 to 2.28$)$ & .22 & 0.97 (0.67 to 1.40$)$ & .88 \\
\hline None & Ref & & Ref & \\
\hline \multicolumn{5}{|c|}{ Carboplatin dose, $\mathrm{mg} / \mathrm{m}^{2}$} \\
\hline$<2,500$ & g & & 0.82 (0.58 to 1.21$)$ & .32 \\
\hline$\geq 2,500$ & g & & 1.35 (0.97 to 1.88 ) & .08 \\
\hline None & Ref & & Ref & \\
\hline \multicolumn{5}{|l|}{ Methotrexate } \\
\hline Yes & 0.83 (0.68 to 0.99$)$ & $.04^{\mathrm{e}}$ & 0.87 (0.78 to 0.97$)$ & .01 \\
\hline \multicolumn{5}{|l|}{ No } \\
\hline \multicolumn{5}{|c|}{ (continued on following page) } \\
\hline
\end{tabular}

Prefrailty $(n=1,953)^{b}$

\begin{tabular}{|c|c|c|c|}
\hline Adjusted PRR ${ }^{\mathrm{c}}(95 \% \mathrm{Cl})$ & $P$ & Adjusted PRR ${ }^{\mathrm{d}}(95 \% \mathrm{Cl})$ & $P$ \\
\hline 1.41 (1.20 to 1.66$)$ & $<.001^{\mathrm{e}}$ & 1.38 (1.25 to 1.52$)$ & $<.001^{\mathrm{e}}$ \\
\hline
\end{tabular}

\begin{tabular}{lccc}
$1.76(1.30$ to 2.42$)$ & $<.001^{\mathrm{e}}$ & $1.46(1.20$ to 1.78$)$ & $<.001^{\mathrm{e}}$ \\
\hline $1.80(1.36$ to 2.35$)$ & $<.001^{\mathrm{e}}$ & $1.25(1.04$ to 1.49$)$ & $.018^{\mathrm{e}}$ \\
\hline $0.96(0.60$ to 1.55$)$ & .88 & $1.03(0.80$ to 1.38$)$ & .83
\end{tabular}

Ref 
TABLE 5. Associations Between Treatment Exposures, Grade 3-4 Chronic Conditions, Lifestyle Factors, and Prefrailty or Frailty Among Survivors (continued)

Frailty $\left(n=681^{) a}\right.$

Factors

Alkylating agents

\begin{tabular}{|c|c|c|c|c|}
\hline Yes & $\mathrm{g}$ & & 1.12 (1.02 to 1.24$)$ & $.02^{\mathrm{e}}$ \\
\hline No & g & & & \\
\hline \multicolumn{5}{|c|}{ Amputation } \\
\hline Yes & $1.41(0.90$ to 2.21$)$ & .13 & 1.17 (0.88 to 1.54$)$ & .26 \\
\hline No & Ref & & & \\
\hline \multicolumn{5}{|c|}{ Lung surgery } \\
\hline Yes & 1.75 (1.28 to 2.38 ) & $<.001^{\mathrm{e}}$ & 1.43 (1.17 to 1.74$)$ & $<.001^{\mathrm{e}}$ \\
\hline No & Ref & & & \\
\hline \multicolumn{5}{|l|}{ Cardiac } \\
\hline Yes & 1.56 (1.24 to 1.98$)$ & $<.001^{\mathrm{e}}$ & 1.28 (1.10 to 1.50$)$ & $.002^{\mathrm{e}}$ \\
\hline No & Ref & & Ref & \\
\hline \multicolumn{5}{|l|}{ Neurologic } \\
\hline Yes & 3.15 (2.51 to 3.95$)$ & $<.001^{\mathrm{e}}$ & 2.35 (2.03 to 2.72 ) & $<.001^{\mathrm{e}}$ \\
\hline No & Ref & & Ref & \\
\hline \multicolumn{5}{|c|}{ Musculoskeletal } \\
\hline Yes & 1.28 (0.86 to 1.92$)$ & .23 & 1.30 (1.01 to 1.64$)$ & $.04^{\mathrm{e}}$ \\
\hline No & Ref & & & \\
\hline \multicolumn{5}{|l|}{ Endocrine } \\
\hline Yes & $1.40(1.10$ to 1.78$)$ & $<.001^{\mathrm{e}}$ & 1.21 (1.03 to 1.42 ) & $.02^{\mathrm{e}}$ \\
\hline No & Ref & & Ref & \\
\hline \multicolumn{5}{|c|}{ Respiratory } \\
\hline Yes & 2.62 (1.58 to 4.35$)$ & $<.001^{\mathrm{e}}$ & 1.50 (0.99 to 2.24$)$ & $.05^{\mathrm{e}}$ \\
\hline No & Ref & & Ref & \\
\hline \multicolumn{5}{|l|}{ SMN } \\
\hline Yes & g & & 1.05 (0.86 to 1.28 ) & .64 \\
\hline No & g & & Ref & \\
\hline \multicolumn{5}{|c|}{ Other chronic conditions } \\
\hline Yes & 1.33 (1.08 to 1.65$)$ & $.007^{\mathrm{e}}$ & 1.33 (1.17 to 1.51$)$ & $<.001^{\mathrm{e}}$ \\
\hline No & Ref & & & \\
\hline \multicolumn{5}{|c|}{ Smoking status ${ }^{f}$} \\
\hline Current & 1.50 (1.23 to 1.82$)$ & $<.001^{\mathrm{e}}$ & 1.44 (1.28 to 1.61$)$ & $<.001^{\mathrm{e}}$ \\
\hline Former & 0.98 (0.76 to 1.30$)$ & .92 & 1.06 (0.92 to 1.26$)$ & .43 \\
\hline Never & Ref & & & \\
\hline \multicolumn{5}{|c|}{ Sedentary behavior } \\
\hline Current & 1.98 (1.54 to 2.54$)$ & $<.001^{\mathrm{e}}$ & 2.48 (2.24 to 2.75$)$ & $<.001^{\mathrm{e}}$ \\
\hline Former & 1.47 (1.24 to 1.76$)$ & $<.001$ & 1.63 (1.41 to 1.88$)$ & $<.001^{\mathrm{e}}$ \\
\hline Never & Ref & & & \\
\hline \multicolumn{5}{|c|}{ (continued on following page) } \\
\hline
\end{tabular}

Prefrailty $(n=1,953)^{b}$

Adjusted PRR $(95 \% \mathrm{Cl})$

$P$

Adjusted PRR $(95 \%$ Cl)

P

Amputation 
TABLE 5. Associations Between Treatment Exposures, Grade 3-4 Chronic Conditions, Lifestyle Factors, and Prefrailty or Frailty Among Survivors (continued)

\begin{tabular}{|c|c|c|c|c|}
\hline \multirow[b]{2}{*}{ Factors } & \multicolumn{2}{|c|}{ Frailty $\left(n=681^{a}\right.$} & \multicolumn{2}{|c|}{ Prefrailty $(n=1,953)^{b}$} \\
\hline & Adjusted PRR $(95 \% \mathrm{Cl})$ & $P$ & Adjusted PRR $(95 \%$ Cl) & $P$ \\
\hline \multicolumn{5}{|c|}{ Obesity (BMI $\geq 30 \mathrm{~kg} / \mathrm{m}^{2}$ ) } \\
\hline Current & 1.47 (1.23 to 1.76$)$ & $<.001^{\mathrm{e}}$ & 1.47 (1.33 to 1.63 ) & $<.001^{\mathrm{e}}$ \\
\hline Former & 1.24 (0.81 to 1.88$)$ & .32 & 1.21 (0.94 to 1.57$)$ & .15 \\
\hline Never & Ref & & & \\
\hline
\end{tabular}

Abbreviations: BMI, body mass index; PRR, prevalence rate ratio; Ref, reference; SMN, second malignant neoplasm.

${ }^{\text {a Frailty }} \geq 3$ components.

${ }^{\text {bPrefrailty }} \geq 2$ components.

${ }^{\mathrm{c}}$ The model includes all treatment exposures, grade 3-4 chronic conditions, and lifestyle factors that were associated with frailty (significant in Tables 2-Tables 4).

${ }^{\mathrm{d}}$ The model includes all treatment exposures, grade 3-4 chronic conditions, and lifestyle factors that were associated with prefrailty (significant in Tables 2-Tables 4).

eIndicates estimates with a false discovery rate $<10$.

fRadiation dose: maximum tumor dose was determined by summing the prescribed dose to all overlapping fields within each respective region. gVariable is not included in the current model.

abdominal/pelvic radiation and frailty. ${ }^{3}$ Importantly, magnitudes of treatment exposure-frailty associations identified in preliminary models were attenuated when organ-specific grade 3-4 chronic conditions and lifestyle factors were added, indicating that burden of chronic disease in this population has a significant impact on physiologic wellbeing and function. Both the prevalence and duration of cardiac, neurologic, respiratory, musculoskeletal, and endocrine conditions and a history/presence of an SMN were associated with frailty. These data suggest that interventions to prevent, delay onset, or remediate chronic disease are needed to preserve function in survivors, given their early exposure to cancer treatments that appear to accelerate the aging process.

The prevalence of frailty among childhood cancer survivors in our study, where frailty was self-reported, was $7.7 \%$ for females and $4.9 \%$ for males, compared with rates $(13.1 \%$ and $2.7 \%$ ) reported in the St Jude Lifetime Cohort, where frailty was assessed clinically, ${ }^{3}$ and in the general population (females, 9.6\%; males, 5.2\%) age $\geq 65$ years. ${ }^{25}$ The presence of frailty in young adult survivors of childhood cancer is concerning, as this aging phenotype is associated with early onset of chronic disease, ${ }^{26-28}$ frequent hospital admissions, and early mortality. 3,9,29,30 Frailty interferes with usual daily activities and negatively affects quality of life. ${ }^{31}$ Screening survivors for frailty and providing interventions to address excessive fatigue, low levels of activity, unexpected weight loss, weakness, or difficulty walking short distances may prevent or delay onset of undesirable health outcomes typically associated with aging.

Our findings expand on previous data by quantifying doses of abdominal ( $>40 \mathrm{~Gy}$ ) or pelvic ( $\geq 34 \mathrm{~Gy}$ ) radiation that confer greatest risk for frailty. Our results also support previous studies that identified cranial radiation and abdominal or pelvic radiation as risk factors for frailty. ${ }^{3}$
Radiation exposures to these sites are associated with endocrine dysfunction ${ }^{32-34}$ and have known associations with reduced pituitary ${ }^{3}$ and gonadal hormone production. ${ }^{35-37}$ Because accounting for the presence of grade 3-4 chronic conditions explained some but not all the associations between radiation exposure and frailty, it is possible that frailty is an early sign of impending clinical disease. In fact, untreated abnormal growth hormone, ${ }^{38}$ testosterone, ${ }^{39,40}$ and estrogen ${ }^{41}$ levels are associated with self-reported fatigue, limited muscular growth and repair, and insufficient energy for participation in regular physical activity, all of which are hallmarks of frailty.

The discovery of an association between platinum exposure and frailty in initial analytic models is unique but was completely explained by grade 3-4 chronic conditions and lifestyle factors. Platinum agents have well-known toxicity profiles $^{42}$ that likely cause early onset of irreversible chronic conditions, leaving exposed survivors with permanent organ system dysfunction, increasing their vulnerability to functional loss. For example, nephrotoxicity, 43,44 hearing loss, ${ }^{45,46}$ vestibular dysfunction, ${ }^{47}$ and peripheral neuropathy ${ }^{48,49}$ are all common effects of platinum exposure and are associated with loss of physical function, sarcopenia, and frailty in other patient populations. ${ }^{50-52}$ Interestingly, sarcoma survivors exposed to either cisplatin or carboplatin, even when renal function is normal, demonstrate lower levels of serum magnesium, ${ }^{53,54}$ a finding suggestive of malnutrition and associated with low lean muscle mass and fatigue. ${ }^{55,56}$

Both lung surgery and amputation were associated with frailty in our study. Structural damage to the lungs or loss of an extremity early in life are acutely associated with respiratory function and with mobility. ${ }^{57-60}$ Previous data from the CCSS and other survivor cohorts indicate that adequate pulmonary function and musculoskeletal integrity are 


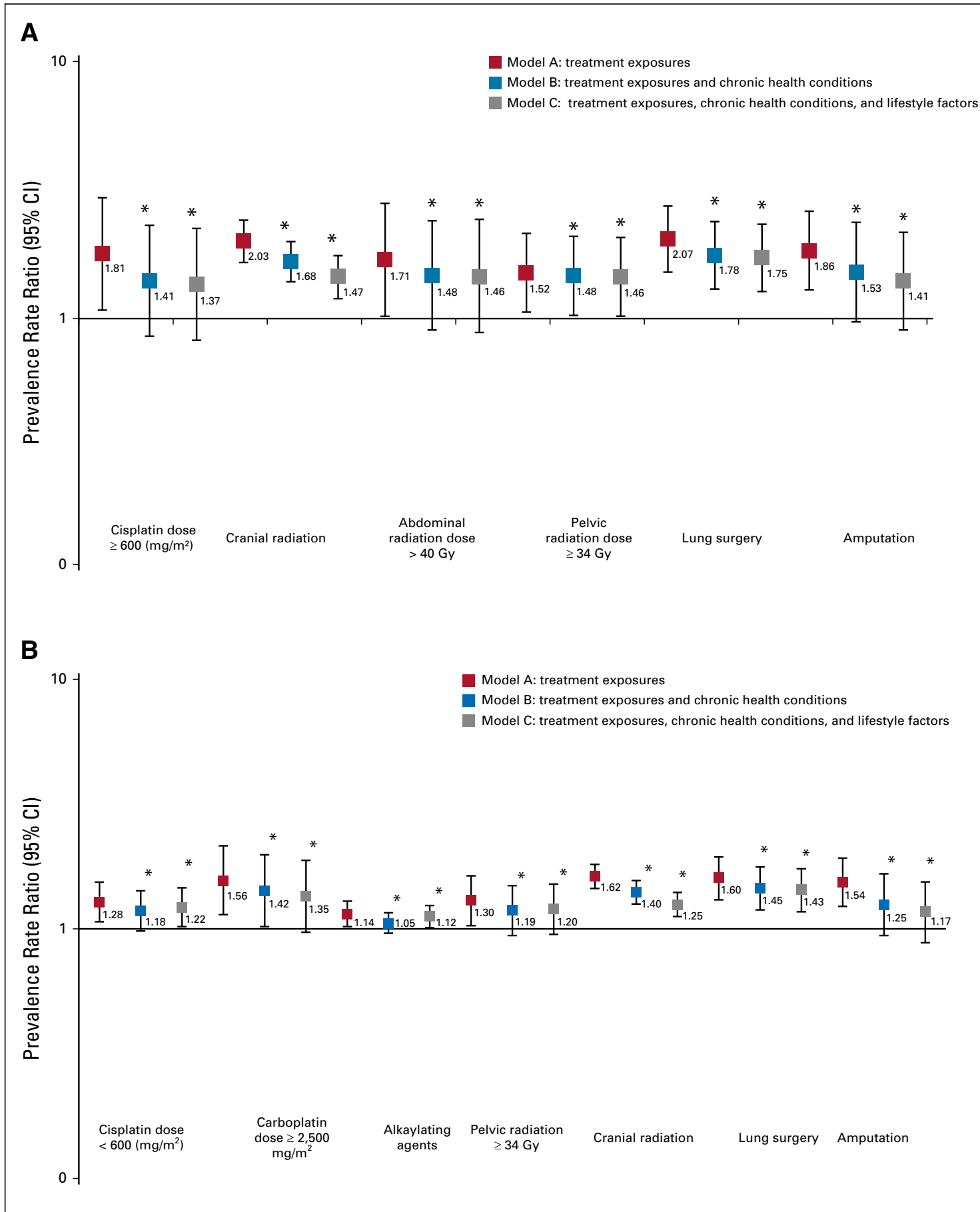

FIG 1. (A) Associations between treatment exposures and frailty (model A), adjusted for grade 3-4 chronic health conditions (model B), and lifestyle (model C). Models adjusted for sex, race/ethnicity, age at diagnosis, and age at assessment. Model A includes treatment exposures. Model B includes treatment exposures (significant in model A) and cardiac, neurologic, respiratory, musculoskeletal, endocrine, and all other chronic conditions. Model $\mathrm{C}$ includes treatment exposures, chronic conditions from model B, and smoking, obesity, and sedentary behavior. Appendix Table A6 (online only) includes data on model fit. (B) Associations between treatment exposures and prefrailty (Model A), adjusted for grade 3-4 chronic health conditions (Model B), and lifestyle (Model C). Models adjusted for sex, race/ethnicity, age at diagnosis, and age at assessment. Model A includes treatment exposures. Model B includes treatment exposures (significant in model A) and cardiac, neurologic, respiratory, musculoskeletal, endocrine, and all other chronic conditions. Model $C$ includes treatment exposures, chronic conditions from model $B$, and smoking, obesity, and sedentary behavior. Appendix Table A7 (online only) includes data on model fit. ( ${ }^{*}$ ) The difference between the model and model A (with treatment exposures only) was significant; $P$ value $<.05$. 
necessary for daily activity and mobility. ${ }^{60-65}$ Over time, associated physical inactivity likely compounds initial impairments, ${ }^{62}$ contributing to development and progression of frailty with age. ${ }^{66}$ In studies of older adults, both respiratory and mobility impairments are associated with frailty. ${ }^{9,16,67}$

As in other adult populations, ${ }^{68-71}$ sedentary lifestyle was associated with prefrailty and frailty in childhood cancer survivors. In addition, smoking and obesity were associated with frailty. However, adding lifestyle factors to evaluation of the association between treatment and frailty when chronic conditions were accounted for did not appreciably change estimates of the association between treatment and frailty. The influence of chronic conditions on development of frailty is substantial, even in the context of modifiable health behaviors, which likely contributed to the development of chronic disease. Lifestyle modification can prevent onset of many chronic diseases. ${ }^{72-74}$ Well-designed interventions that target physical activity, smoking cessation, and weight control, specifically designed for survivors whose therapy exposures are unalterable and increase vulnerability to disease, are needed. Siblings may also benefit from interventions that promote a healthy lifestyle, particularly as they are more likely than survivors to adopt unhealthy behaviors.

Although our study uniquely characterizes and provides new data about risk factors for frailty among a large childhood cancer survivor cohort, there are potential limitations. First, not all eligible survivors participated; our prevalence estimates may be inflated or deflated if frail

\section{AFFILIATIONS}

${ }^{1}$ St Jude Children's Research Hospital, Memphis, TN

${ }^{2}$ Fred Hutchinson Cancer Research Center, Seattle, WA

${ }^{3}$ National Cancer Institute, Rockville, MD

${ }^{4}$ Baylor College of Medicine, Houston, TX

${ }^{5}$ The University of Texas MD Anderson Cancer Center, Houston, TX

${ }^{6}$ Duke University, Durham, NC

${ }^{7}$ University of Alabama at Birmingham, Birmingham, AL

${ }^{8}$ University Health Network, Toronto, Canada

${ }^{9}$ Hospital for Sick Children, Toronto, Canada

\section{CORRESPONDING AUTHOR}

Kirsten K. Ness, MPH, PhD, Epidemiology and Cancer Control, St Jude Children's Research Hospital, 262 Danny Thomas PI, MS-735, Memphis, TN 38105; Twitter: @StJudeResearch; e-mail: kiri.ness@ stjude.org.

\section{SUPPORT}

Support was provided to St Jude Children's Research Hospital by the National Cancer Institute Cancer Center Support (CORE) Grant No. CA55727 (G.T.A., principal investigator) and Grant No. CA21765 (C. Roberts, principal investigator), and the American Lebanese Syrian Associated Charities. health is associated with participation. Second, data are self-reported, subject to reporting and recall bias, even though our results align with estimates from the St Jude Lifetime Cohort, where frailty ascertainment is based on clinical measures. ${ }^{3}$ Third, survival bias is possible; the frailest survivors likely did not live long enough to participate. However, a sensitivity analysis, classifying participants who died after baseline survey completion and before follow-up 5 as frail did not change our conclusions (Appendix Tables A13-Tables A16, online only). Fourth, therapies for many childhood cancers have evolved over time; our results may not be directly generalizable to more recently treated populations. However, traditional chemotherapeutics and radiotherapy continue to be the backbone of cancer treatment of most childhood malignancies. ${ }^{75,76}$ Finally, as the prevalence of frailty among siblings was low, we were unable to evaluate risk factors for this outcome among siblings.

In conclusion, childhood cancer survivors reported a higher prevalence of frailty compared with siblings, suggesting that specific cancer therapies place survivors at early risk for development of an aging phenotype. Those associations are mediated partially by chronic disease, physical activity, smoking, and obesity. Our results suggest that interventions designed to delay onset or remediate chronic disease and/ or that promote healthy lifestyle choices are needed to prevent development of frailty in childhood cancer survivors, where early onset of chronic conditions shortens life expectancy.

AUTHORS' DISCLOSURES OF POTENTIAL CONFLICTS OF INTEREST AND DATA AVAILABILITY STATEMENT

Disclosures provided by the authors and data availability statement (if applicable) are available with this article at DOI https://doi.org/10.1200/ JCO.19.01226

\section{AUTHOR CONTRIBUTIONS}

Conception and design: Samah Hayek, Wendy M. Leisenring, Maria Monica Gramatges, Kevin C. Oeffinger, Melissa M. Hudson, Leslie L. Robison, Paul C. Nathan, Gregory T. Armstrong, Kirsten K. Ness Financial support: Melissa M. Hudson, Leslie L. Robison, Gregory T. Armstrong

Administrative support: Melissa M. Hudson, Leslie L. Robison, Gregory T. Armstrong

Provision of study material or patients: Smita Bhatia, Melissa M. Hudson, Leslie L. Robison, Gregory T. Armstrong

Collection and assembly of data: Rebecca M. Howell, Melissa M. Hudson, Leslie L. Robison, Gregory T. Armstrong

Data analysis and interpretation: Samah Hayek, Todd M. Gibson, Wendy M. Leisenring, Jennifer L. Guida, Philip J. Lupo, Smita Bhatia, Kim Edelstein, Melissa M. Hudson, Paul C. Nathan, Yutaka Yasui, Kevin R. Krull, Gregory T. Armstrong, Kirsten K. Ness

Manuscript writing: All authors

Final approval of manuscript: All authors

Accountable for all aspects of the work: All authors 


\section{REFERENCES}

1. Howlader N, Noone AM, Krapcho M, et al: Section 28: Childhood Cancer by Site: Incidence, Survival, and Mortality, in SEER Cancer Statistics Review, 19752016. Bethesda, MD, National Cancer Institute, 2018 https://seer.cancer.gov/csr/1975_2016/results_merged/sect_28_childhood_cancer.pdf

2. Bhakta N, Liu Q, Ness KK, et al: The cumulative burden of surviving childhood cancer: An initial report from the St Jude Lifetime Cohort Study (SJLIFE). Lancet 390:2569-2582, 2017

3. Ness KK, Krull KR, Jones KE, et al: Physiologic frailty as a sign of accelerated aging among adult survivors of childhood cancer: A report from the St Jude Lifetime cohort study. J Clin Oncol 31:4496-4503, 2013

4. Song X, Mitnitski A, Rockwood K: Prevalence and 10-year outcomes of frailty in older adults in relation to deficit accumulation. J Am Geriatr Soc 58:681-687, 2010

5. Leisenring WM, Mertens AC, Armstrong GT, et al: Pediatric cancer survivorship research: Experience of the Childhood Cancer Survivor Study. J Clin Oncol 27: 2319-2327, 2009

6. Robison LL, Mertens AC, Boice JD, et al: Study design and cohort characteristics of the Childhood Cancer Survivor Study: A multi-institutional collaborative project. Med Pediatr Oncol 38:229-239, 2002

7. Robison LL, Armstrong GT, Boice JD, et al: The Childhood Cancer Survivor Study: A National Cancer Institute-supported resource for outcome and intervention research. J Clin Oncol 27:2308-2318, 2009

8. Childhood Cancer Survivor Study: Baseline and Follow-Up Questionnaires. The Childhood Cancer Survivor Study, St Jude Children's Research Hospital, 2019. https://ccss.stjude.org/tools-and-documents/questionnaires/baseline-and-follow-up-questionnaires.html

9. Fried LP, Tangen CM, Walston J, et al: Frailty in older adults: Evidence for a phenotype. J Gerontol A Biol Sci Med Sci 56:M146-M156, 2001

10. Ware JE Jr, Sherbourne CD: The MOS 36-item short-form health survey (SF-36). I. Conceptual framework and item selection. Med Care 30:473-483, 1992

11. Centers for Disease Control and Prevention: National Health and Nutrition Examination Survey 2013-2014 Data Documentation, Codebook, and Frequencies. https://wwwn.cdc.gov/Nchs/Nhanes/2013-2014/PAQ_H.htm\#Appendix_1._Suggested_MET_Scores

12. Ainsworth BE, Haskell WL, Herrmann SD, et al: 2011 Compendium of Physical Activities: A second update of codes and MET values. Med Sci Sports Exerc 43: 1575-1581, 2011

13. US Department of Health Human Services: 2015-2020 Dietary Guidelines for Americans. https://health.gov/dietaryguidelines/2015/

14. Centers for Disease Control and Prevention: Behavioral Risk Factor Surveillance System Survey Questionnaire 2012: https://www.cdc.gov/brfss/questionnaires/ pdf-ques/2012_BRFSS.pdf

15. Centers for Disease Control and Prevention: Behavioral Risk Factor Surveillance System, 2013 Codebook Report 2013

16. Vaz Fragoso CA, Enright PL, McAvay G, et al: Frailty and respiratory impairment in older persons. Am J Med 125:79-86, 2012

17. National Cancer Institute: Common Terminology Criteria for Adverse Events (CTCAE) Version 4.03. https://ctep.cancer.gov/protocoldevelopment/ electronic_applications/ctc.htm

18. Armstrong GT, Kawashima T, Leisenring W, et al: Aging and risk of severe, disabling, life-threatening, and fatal events in the childhood cancer survivor study. J Clin Oncol 32:1218-1227, 2014

19. Zeger SL, Liang K-Y: Longitudinal data analysis for discrete and continuous outcomes. Biometrics 42:121-130, 1986

20. McCulloch CE: Generalized linear mixed models. NSF-CBMS Regional Conference Series in Probability and Statistics. 7:i-84, 2003

21. Baron RM, Kenny DA: The moderator-mediator variable distinction in social psychological research: Conceptual, strategic, and statistical considerations. J Pers Soc Psychol 51:1173-1182, 1986

22. Akaike H: Factor analysis and AIC, in Parzen E., Tanabe K, Kitagawa G (eds): Selected Papers of Hirotugu Akaike. New York, NY, Springer, 1987, pp. 371-386

23. Jöreskog KG, Sörbom D: LISREL 8: Structural Equation Modeling With the SIMPLIS Command Language. Chicago, IL, Scientific Software International, 1993

24. Benjamini Y, Hochberg Y: Controlling the false discovery rate: A practical and powerful approach to multiple testing. J R Stat Soc Series B Stat Methodol 57: 289-300, 1995

25. Collard RM, Boter H, Schoevers RA, et al: Prevalence of frailty in community-dwelling older persons: A systematic review. J Am Geriatr Soc 60:1487-1492, 2012

26. Weiss CO: Frailty and chronic diseases in older adults. Clin Geriatr Med 27:39-52, 2011

27. Newman AB, Gottdiener JS, Mcburnie MA, et al: Associations of subclinical cardiovascular disease with frailty. J Gerontol A Biol Sci Med Sci 56:M158-M166, 2001

28. Walston J, McBurnie MA, Newman A, et al: Frailty and activation of the inflammation and coagulation systems with and without clinical comorbidities: Results from the Cardiovascular Health Study. Arch Intern Med 162:2333-2341, 2002

29. Henderson TO, Ness KK, Cohen HJ: Accelerated aging among cancer survivors: From pediatrics to geriatrics. Am Soc Clin Oncol Educ Book 34:e423-e430, 2014

30. Covinsky KE, Hilton J, Lindquist K, et al: Development and validation of an index to predict activity of daily living dependence in community-dwelling elders. Med Care 44:149-157, 2006

31. Boyd CM, Xue QL, Simpson CF, et al: Frailty, hospitalization, and progression of disability in a cohort of disabled older women. Am J Med 118:1225-1231, 2005

32. Nandagopal R, Laverdière C, Mulrooney D, et al: Endocrine late effects of childhood cancer therapy: A report from the Children's Oncology Group. Horm Res 69: 65-74, 2008

33. Meacham L: Endocrine late effects of childhood cancer therapy. Curr Probl Pediatr Adolesc Health Care 33:217-242, 2003

34. Gleeson HK, Shalet SM: The impact of cancer therapy on the endocrine system in survivors of childhood brain tumours. Endocr Relat Cancer 11:589-602, 2004

35. Chiarelli AM, Marrett LD, Darlington G: Early menopause and infertility in females after treatment for childhood cancer diagnosed in $1964-1988$ in Ontario, Canada. Am J Epidemiol 150:245-254, 1999

36. Antal Z, Sklar CA: Gonadal function and fertility among survivors of childhood cancer. Endocrinol Metab Clin North Am 44:739-749, 2015

37. Rose SR, Horne VE, Howell J, et al: Late endocrine effects of childhood cancer. Nat Rev Endocrinol 12:319-336, 2016

38. Chemaitilly W, Li Z, Huang S, et al: Anterior hypopituitarism in adult survivors of childhood cancers treated with cranial radiotherapy: A report from the St Jude Lifetime Cohort study. J Clin Oncol 33:492-500, 2015

39. Herbst KL, Bhasin S: Testosterone action on skeletal muscle. Curr Opin Clin Nutr Metab Care 7:271-277, 2004

40. Hyde Z, Flicker L, Almeida OP, et al: Low free testosterone predicts frailty in older men: The health in men study. J Clin Endocrinol Metab 95:3165-3172, 2010

41. Lemoine S, Granier P, Tiffoche C, et al: Estrogen receptor alpha mRNA in human skeletal muscles. Med Sci Sports Exerc 35:439-443, 2003

42. Lokich J, Anderson N: Carboplatin versus cisplatin in solid tumors: An analysis of the literature. Ann Oncol 9:13-21, 1998 
43. Miller RP, Tadagavadi RK, Ramesh G, et al: Mechanisms of cisplatin nephrotoxicity. Toxins (Basel) 2:2490-2518, 2010

44. Karasawa T, Steyger PS: An integrated view of cisplatin-induced nephrotoxicity and ototoxicity. Toxicol Lett 237:219-227, 2015

45. Clemens E, de Vries AC, Am Zehnhoff-Dinnesen A, et al: Hearing loss after platinum treatment is irreversible in noncranial irradiated childhood cancer survivors. Pediatr Hematol Oncol 34:120-129, 2017

46. Kolinsky DC, Hayashi SS, Karzon R, et al: Late onset hearing loss: A significant complication of cancer survivors treated with Cisplatin containing chemotherapy regimens. J Pediatr Hematol Oncol 32:119-123, 2010

47. Ding D, Jiang H, Zhang J, et al: Cisplatin-induced vestibular hair cell lesion-less damage at high doses. J Otol 13:115-121, 2018

48. Kawakami K, Tunoda T, Takiguchi T, et al: Factors exacerbating peripheral neuropathy induced by paclitaxel plus carboplatin in non-small cell lung cancer. Oncol Res 20:179-185, 2012

49. Argyriou AA, Polychronopoulos $P$, Koutras A, et al: Clinical and electrophysiological features of peripheral neuropathy induced by administration of cisplatin plus paclitaxel-based chemotherapy. Eur J Cancer Care (Engl) 16:231-237, 2007

50. Anand S, Johansen KL, Kurella Tamura M: Aging and chronic kidney disease: The impact on physical function and cognition. J Gerontol A Biol Sci Med Sci 69: 315-322, 2014

51. Gopinath B, Schneider J, McMahon CM, et al: Severity of age-related hearing loss is associated with impaired activities of daily living. Age Ageing 41:195-200, 2012

52. Kim JK, Choi SR, Choi MJ, et al: Prevalence of and factors associated with sarcopenia in elderly patients with end-stage renal disease. Clin Nutr 33:64-68, 2014

53. Marina NM, Poquette CA, Cain AM, et al: Comparative renal tubular toxicity of chemotherapy regimens including ifosfamide in patients with newly diagnosed sarcomas. J Pediatr Hematol Oncol 22:112-118, 2000

54. Stöhr W, Paulides M, Bielack S, et al: Nephrotoxicity of cisplatin and carboplatin in sarcoma patients: A report from the late effects surveillance system. Pediatr Blood Cancer 48:140-147, 2007

55. Kaiser M, Bandinelli S, Lunenfeld B: Frailty and the role of nutrition in older people. A review of the current literature. Acta Biomed 81:37-45, 2010 (suppl 1)

56. Artaza-Artabe I, Sáez-López P, Sánchez-Hernández N, et al: The relationship between nutrition and frailty: Effects of protein intake, nutritional supplementation, vitamin D and exercise on muscle metabolism in the elderly. A systematic review. Maturitas 93:89-99, 2016

57. Armenian SH, Landier W, Francisco L, et al: Long-term pulmonary function in survivors of childhood cancer. J Clin Oncol 33:1592-1600, 2015

58. Fernandez-Pineda I, Hudson MM, Pappo AS, et al: Long-term functional outcomes and quality of life in adult survivors of childhood extremity sarcomas: A report from the St. Jude Lifetime Cohort Study. J Cancer Surviv 11:1-12, 2017

59. Denbo JW, Zhu L, Srivastava D, et al: Long-term pulmonary function after metastasectomy for childhood osteosarcoma: A report from the St Jude lifetime cohort study. J Am Coll Surg 219:265-271, 2014

60. Nicholson HS, Mulvihill JJ, Byrne J: Late effects of therapy in adult survivors of osteosarcoma and Ewing's sarcoma. Med Pediatr Oncol 20:6-12, 1992

61. Hudson MM, Mertens AC, Yasui Y, et al: Health status of adult long-term survivors of childhood cancer: A report from the Childhood Cancer Survivor Study. JAMA 290:1583-1592, 2003

62. Ness KK, Mertens AC, Hudson MM, et al: Limitations on physical performance and daily activities among long-term survivors of childhood cancer. Ann Intern Med 143:639-647, 2005

63. Bielack SS, Kempf-Bielack B, Delling G, et al: Prognostic factors in high-grade osteosarcoma of the extremities or trunk: An analysis of 1,702 patients treated on neoadjuvant cooperative osteosarcoma study group protocols. J Clin Oncol 20:776-790, 2002

64. Reulen RC, Winter DL, Lancashire ER, et al: Health-status of adult survivors of childhood cancer: A large-scale population-based study from the British Childhood Cancer Survivor Study. Int J Cancer 121:633-640, 2007

65. Jenney ME, Faragher EB, Jones PH, et al: Lung function and exercise capacity in survivors of childhood leukaemia. Med Pediatr Oncol 24:222-230, 1995

66. Ness KK, Leisenring WM, Huang S, et al: Predictors of inactive lifestyle among adult survivors of childhood cancer: A report from the Childhood Cancer Survivor Study. Cancer 115:1984-1994, 2009

67. Park SK, Richardson CR, Holleman RG, et al: Frailty in people with COPD, using the National Health and Nutrition Evaluation Survey dataset (2003-2006). Heart Lung 42:163-170, 2013

68. Blodgett J, Theou O, Kirkland S, et al: The association between sedentary behaviour, moderate-vigorous physical activity and frailty in NHANES cohorts. Maturitas 80:187-191, 2015

69. da Silva Coqueiro R, de Queiroz BM, Oliveira DS, et al: Cross-sectional relationships between sedentary behavior and frailty in older adults. J Sports Med Phys Fitness 57:825-830, 2017

70. Hubbard RE, Searle SD, Mitnitski A, et al: Effect of smoking on the accumulation of deficits, frailty and survival in older adults: A secondary analysis from the Canadian Study of Health and Aging. J Nutr Health Aging 13:468-472, 2009

71. García-Esquinas E, José García-García F, León-Muñoz LM, et al: Obesity, fat distribution, and risk of frailty in two population-based cohorts of older adults in Spain. Obesity (Silver Spring) 23:847-855, 2015

72. Null G, Pennesi L: Diet and lifestyle intervention on chronic moderate to severe depression and anxiety and other chronic conditions. Complement Ther Clin Pract 29:189-193, 2017

73. Stampfer MJ, Hu FB, Manson JE, et al: Primary prevention of coronary heart disease in women through diet and lifestyle. N Engl J Med 343:16-22, 2000

74. Aldana SG, Greenlaw RL, Diehl HA, et al: The behavioral and clinical effects of therapeutic lifestyle change on middle-aged adults. Prev Chronic Dis 3:A05, 2006

75. Hudson MM, Neglia JP, Woods WG, et al: Lessons from the past: Opportunities to improve childhood cancer survivor care through outcomes investigations of historical therapeutic approaches for pediatric hematological malignancies. Pediatr Blood Cancer 58:334-343, 2012

76. Green DM, Kun LE, Matthay KK, et al: Relevance of historical therapeutic approaches to the contemporary treatment of pediatric solid tumors. Pediatr Blood Cancer 60:1083-1094, 2013 
AUTHORS' DISCLOSURES OF POTENTIAL CONFLICTS OF INTEREST

\section{Prevalence and Predictors of Frailty in Childhood Cancer Survivors and Siblings: A Report From the Childhood Cancer Survivor Study}

The following represents disclosure information provided by authors of this manuscript. All relationships are considered compensated unless otherwise noted. Relationships are self-held unless noted. I = Immediate Family Member, Inst = My Institution. Relationships may not relate to the subject matter of this manuscript. For more information about ASCO's conflict of interest policy, please refer to www.asco.org/rwc or ascopubs.org/journal/jco/site/ifc.

Open Payments is a public database containing information reported by companies about payments made to US-licensed physicians (Open Payments).

Melissa M. Hudson

Consulting or Advisory Role: Oncology Research Information Exchange Network, Princess Máxima Center, SurvivorLink
Kevin R. Krull

Patents, Royalties, Other Intellectual Property: Royalties from Wolters Kluwer No other potential conflicts of interest were reported. 


\section{APPENDIX}

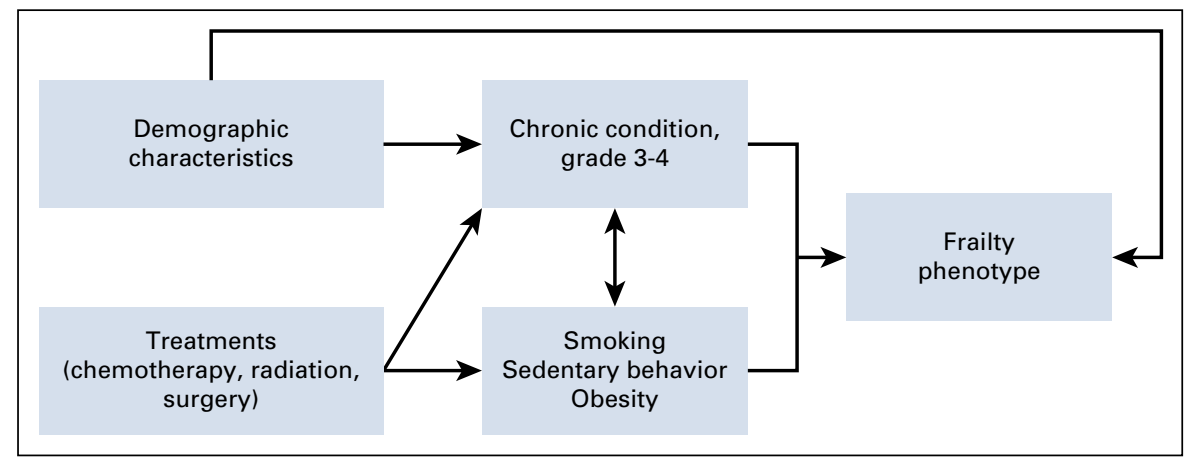

FIG A1. Hypothesized model.

Completed baseline questionnaire, alive at

follow-up 5 , and $\geq 18$ years old at follow-up 5 $(n=20,834)$

$\begin{array}{lr}\text { Nonresponder } & (\mathrm{n}=6,355) \\ \text { Active refusal } & (\mathrm{n}=2,021) \\ \text { Lost to follow-up } & (\mathrm{n}=103)\end{array}$

Lost to follow-up

Lost to follow-up at $(n=1,083)$

the time of the

survey

Potential participants

( $n=11,272)$

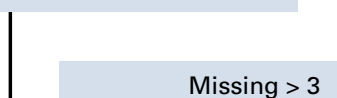

components of frailty $(n=373)$

Final sample size

( $N=10,899$ )

FIG A2. Selection of study participants from Childhood Cancer Survivors Study: survivors. 


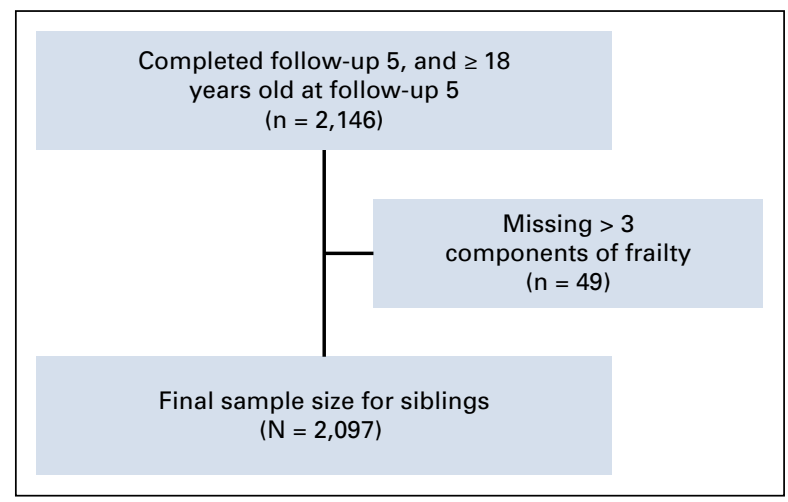

FIG A3. Selection of study participants from Childhood Cancer Survivors Study: siblings.

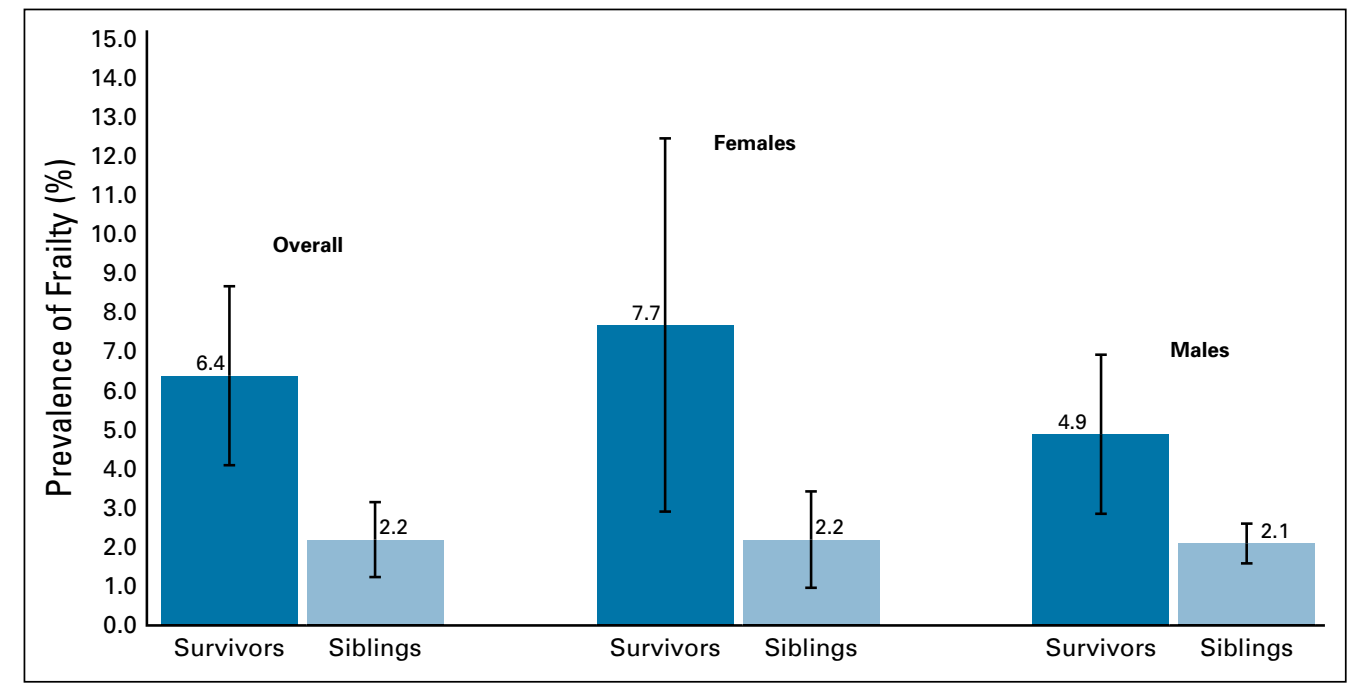

FIG A4. Age-adjusted prevalence of frailty by sex. Weighted percentages and $95 \%$ Cls are presented. Frailty $\geq 3$ components. 


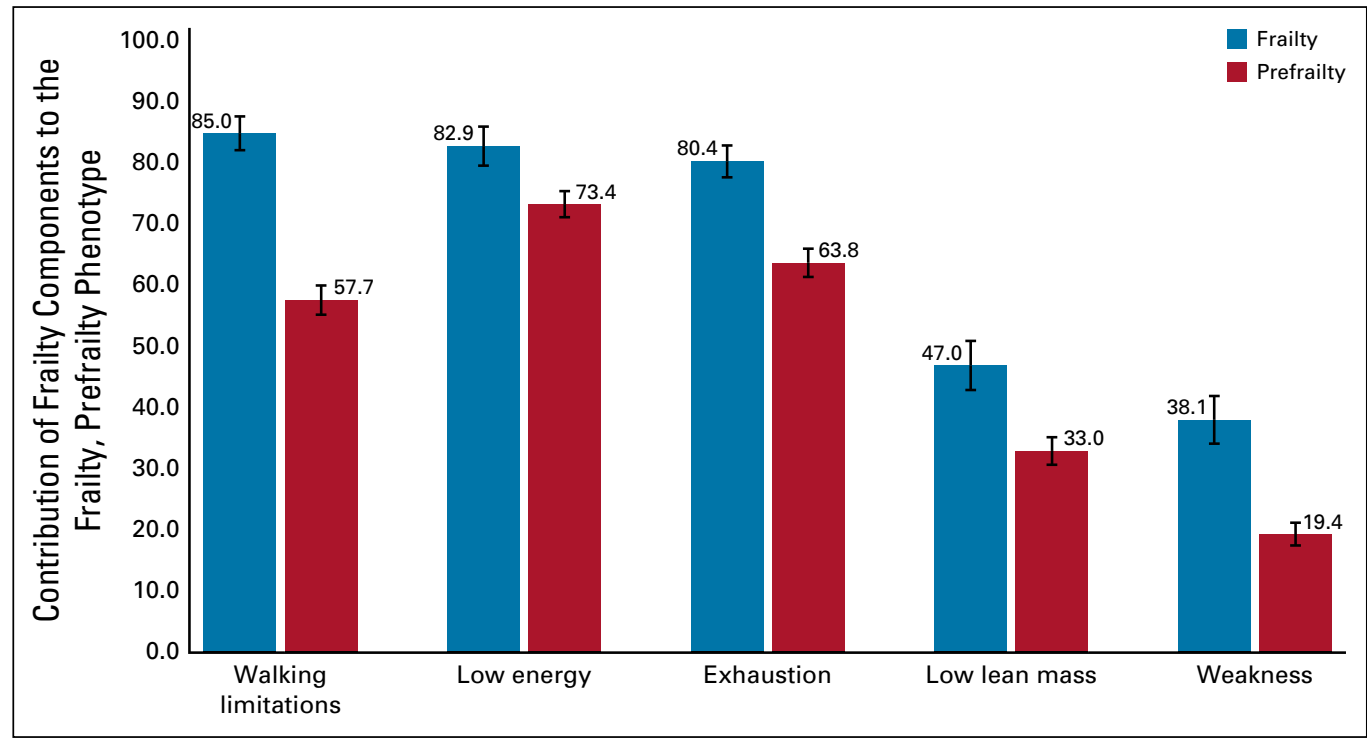

FIG A5. Contribution of frailty components to the frailty and prefrailty phenotypes. Weighted percentages and $95 \% \mathrm{Cls}$ are presented. Frailty $\geq 3$ components; prefrailty $\geq 2$ components.

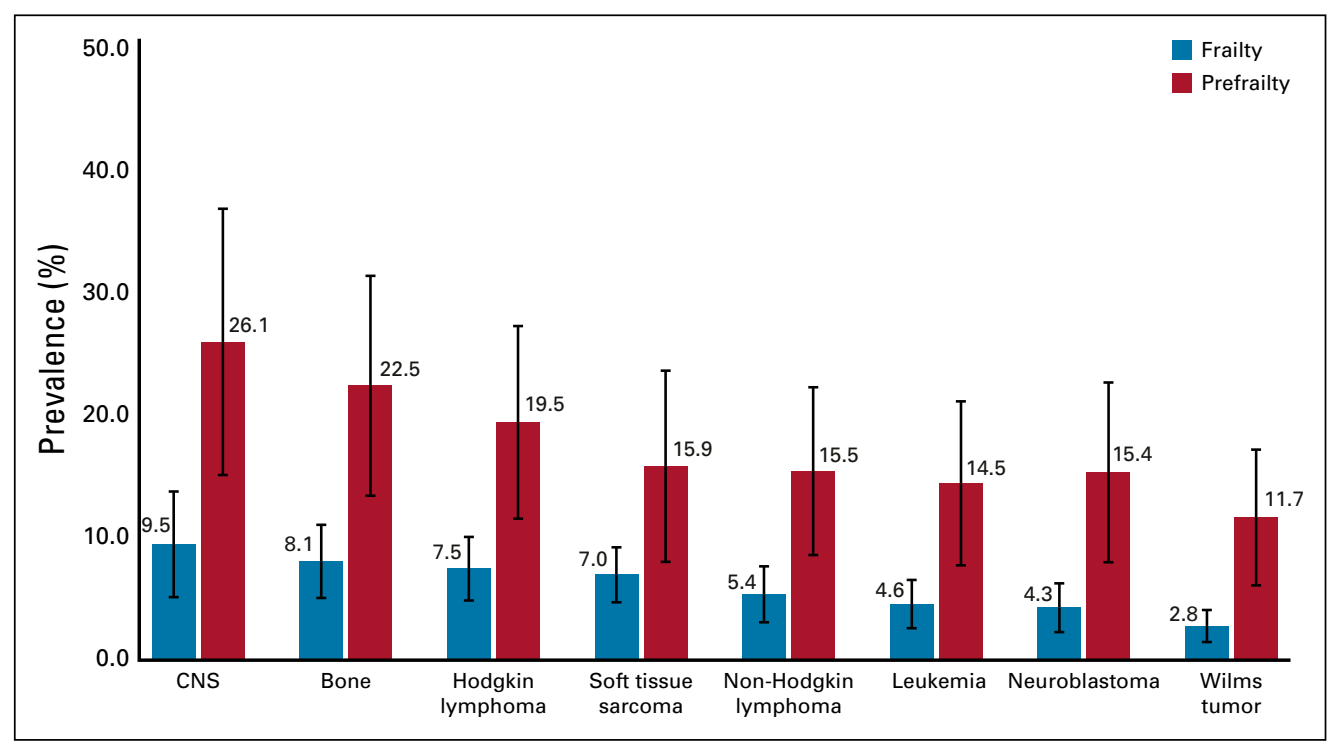

FIG A6. Age-adjusted prevalence of frailty and prefrailty among childhood cancer survivors by primary diagnosis. Weighted percentages and $95 \% \mathrm{Cls}$ are presented. Frailty $\geq 3$ components; prefrailty $\geq 2$ components. 


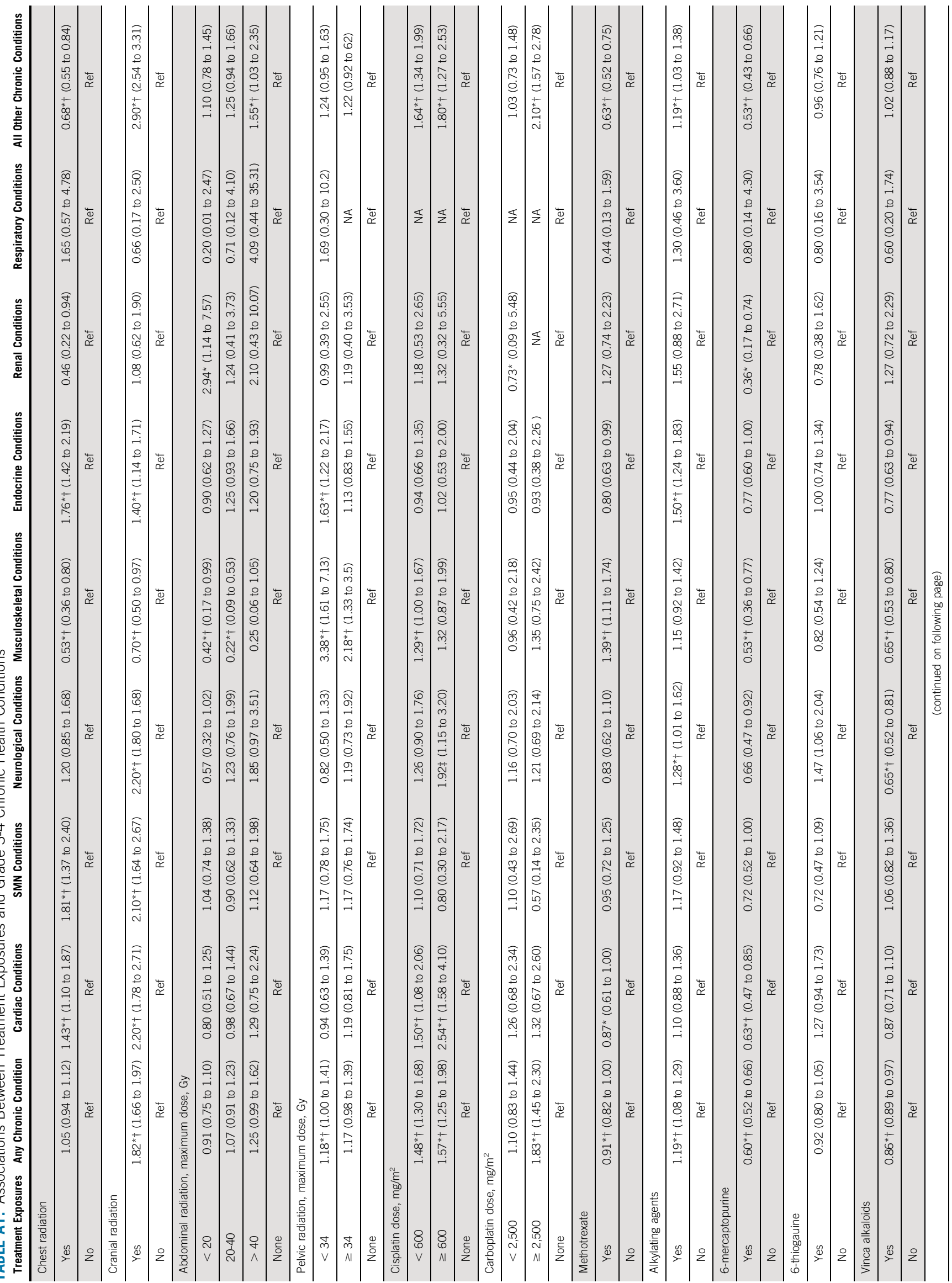




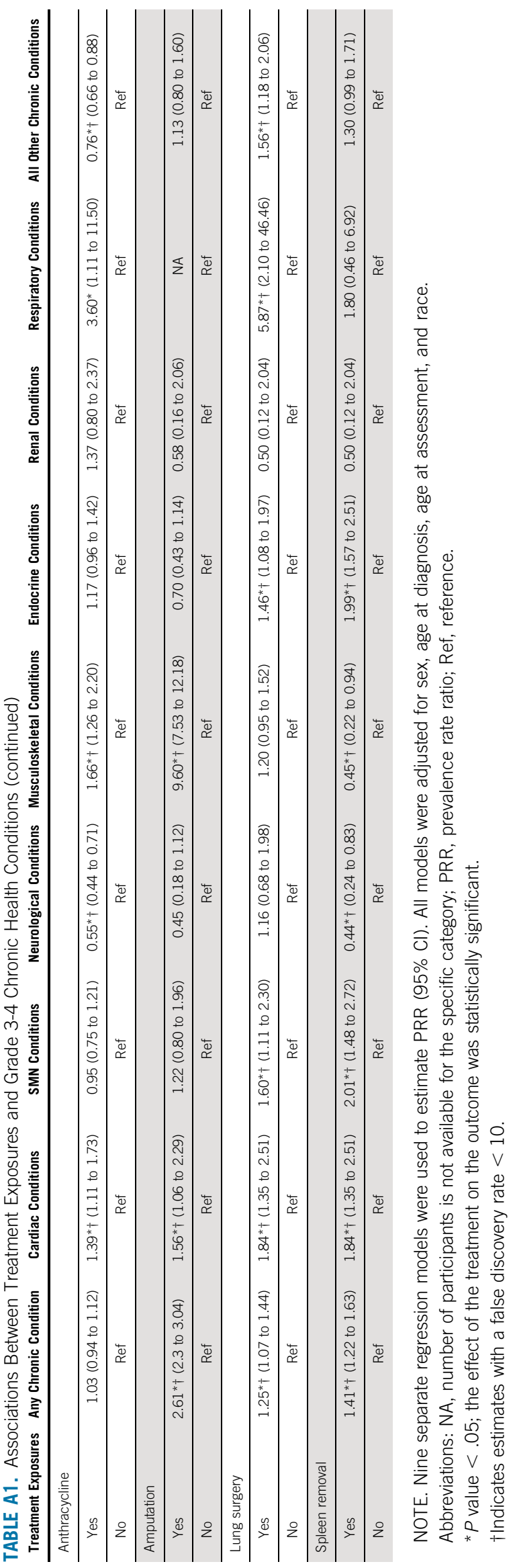




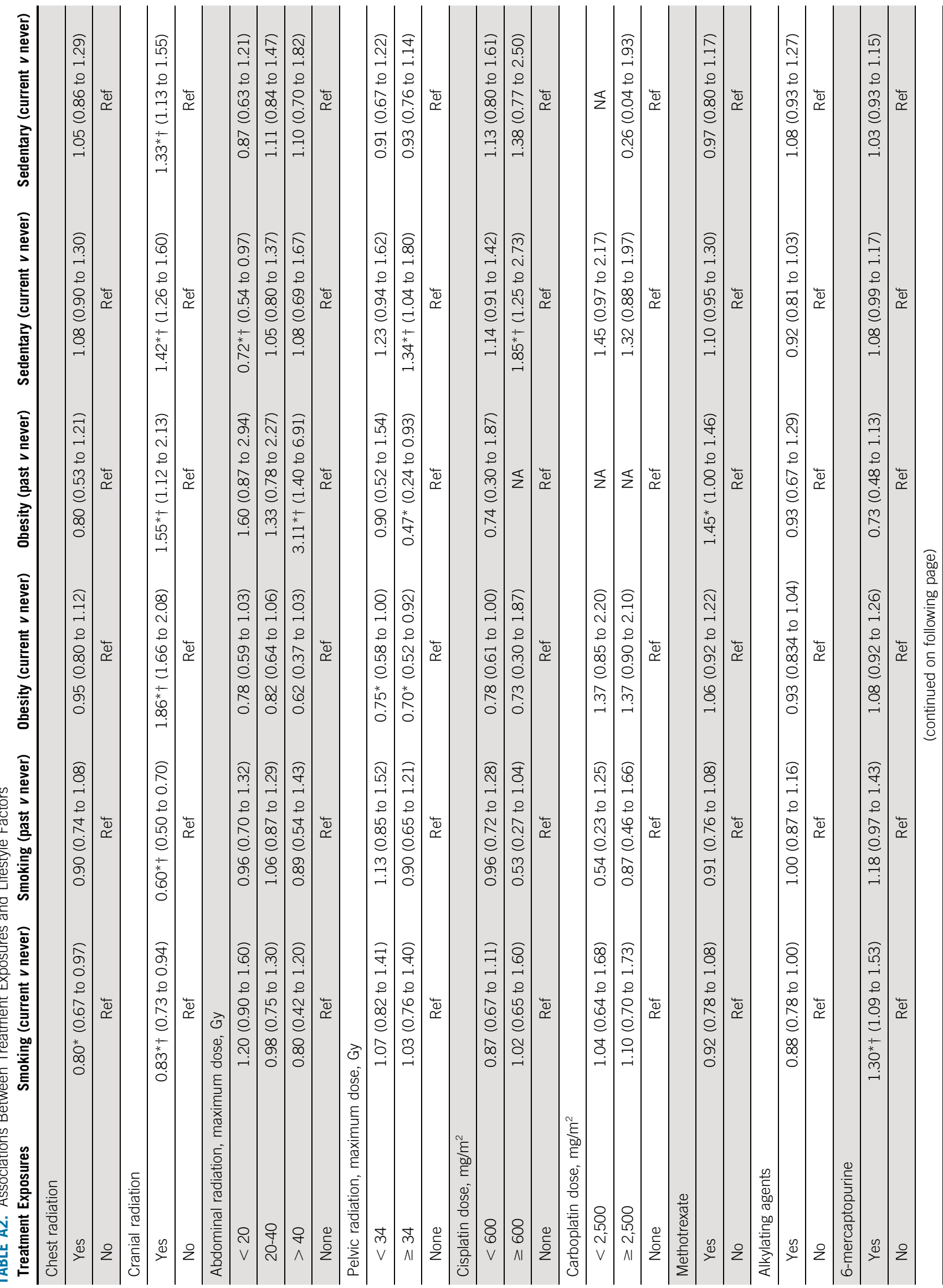




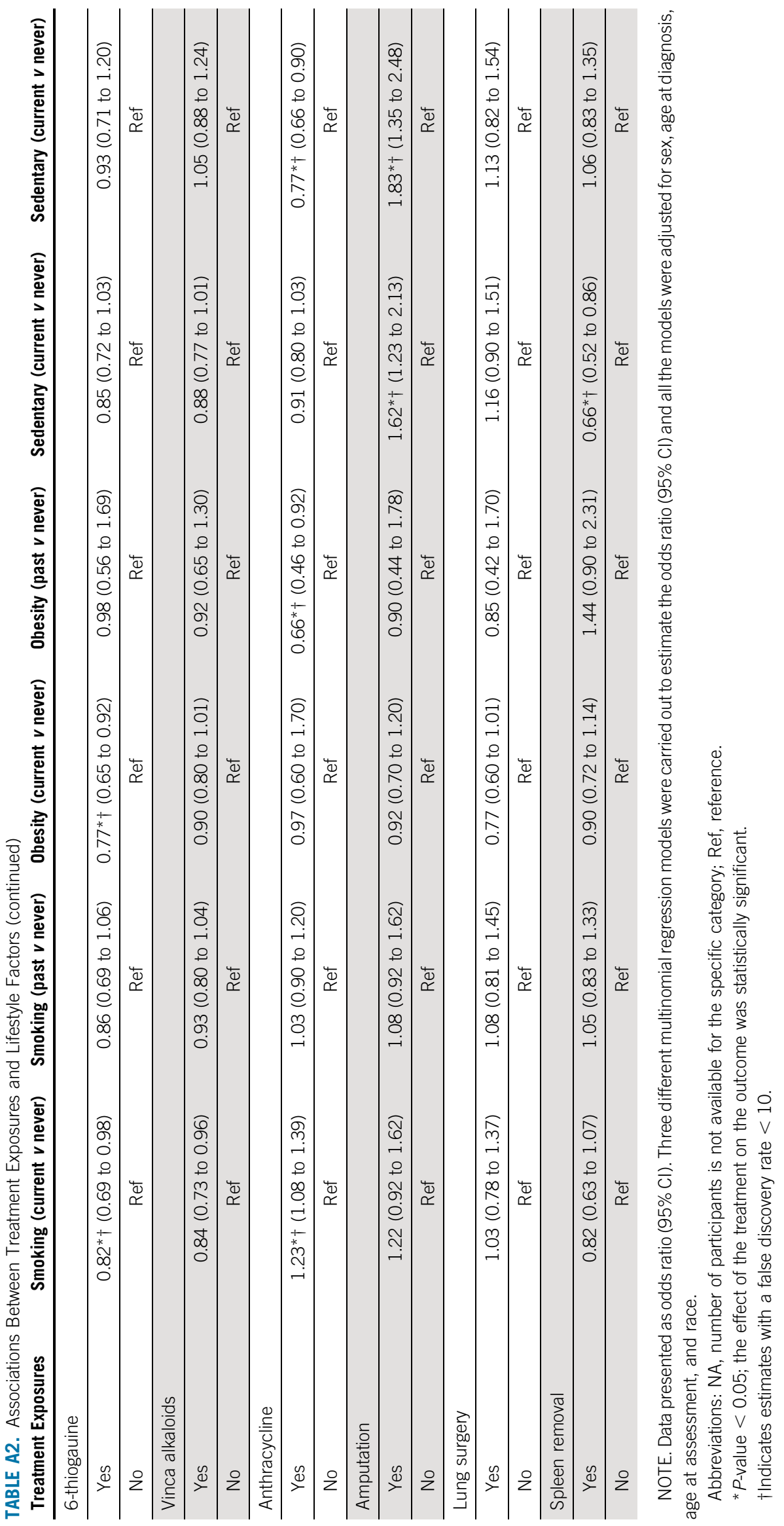


TABLE A3. Characteristics of Participants and Nonparticipants Characteristics

Participants ( $N=10,899)$

Nonparticipants $(n=9,935)$

$\boldsymbol{P}$

\begin{tabular}{|c|c|c|c|}
\hline Mean age at diagnosis, years (SD) & $8.05(6.0)$ & $7.00(5.7)$ & $<.001$ \\
\hline Sex & & & $<.001$ \\
\hline Female & $5,709(52.3)$ & $4,142(41.5)$ & \\
\hline Male & $5,190(47.7)$ & $5,793(58.5)$ & \\
\hline Race/ethnicity & & & $<.001$ \\
\hline Non-Hispanic white & $9,401(85.7)$ & 7,544 (74.6) & \\
\hline Non-Hispanic black & $452(4.3)$ & $828(8.4)$ & \\
\hline Hispanic & $661(6.3)$ & $915(10.2)$ & \\
\hline Other* & $385(3.7)$ & $648(7.0)$ & \\
\hline Site at primary diagnosis & & & $<.001$ \\
\hline Leukemia & $3,276(38.7)$ & $3,202(42.0)$ & \\
\hline Hodgkin lymphoma & $1,338(10.8)$ & $938(8.1)$ & \\
\hline Non-Hodgkin lymphoma & $904(7.3)$ & $881(7.6)$ & \\
\hline CNS & $1,905(15.3)$ & $1,626(14.0)$ & \\
\hline Neuroblastoma & $790(6.4)$ & $880(7.6)$ & \\
\hline Wilms tumor & $1,018(8.2)$ & $997(8.6)$ & \\
\hline Soft tissue sarcoma & $740(6.0)$ & $696(6.0)$ & \\
\hline Bone tumor & $928(7.5)$ & $715(6.20$ & \\
\hline
\end{tabular}

NOTE. Data shown as No. (\%) unless otherwise noted. Unweighted frequencies and weighted \% are presented. Abbreviation: SD, standard deviation.

*Other: includes Asian and not-specified race. 


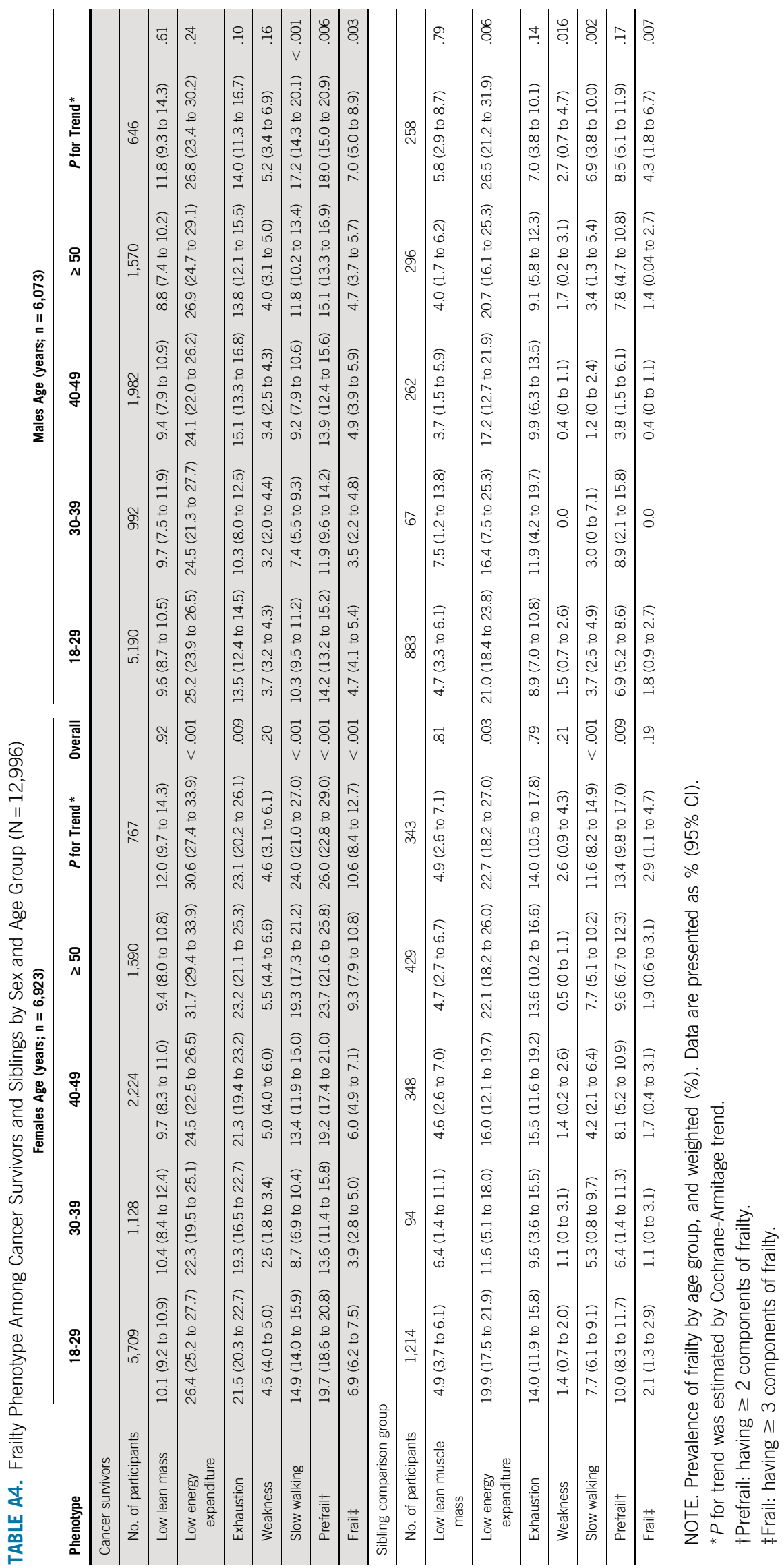


TABLE A5. Associations Between Length of Grade 3-4 Chronic Health Conditions and Frailty Among Survivors

Frailty $(n=681)^{*}$

Prefrailty $(n=1,953) \dagger$

5-Year Duration of Organ-Specific Chronic Condition

\begin{tabular}{ccccc}
\hline Adjusted PRR $\ddagger(\mathbf{9 5 \%} \mathbf{C l})$ & $\boldsymbol{P}$ & & Adjusted PRR $\ddagger(\mathbf{9 5 \%} \mathbf{C l})$ & $\boldsymbol{P}$ \\
\hline $1.02(1.01$ to 1.03$)$ & $<.001$ & & $1.01(1.01$ to 1.21$)$ & $<.001$ \\
\hline $1.05(1.05$ to 1.04$)$ & $<.001$ & $1.04(1.03$ to 1.04$)$ & $<.001$ \\
\hline $1.02(1.01$ to 1.03$)$ & $<.001$ & $1.01(1.08$ to 1.02$)$ & $<.001$ \\
\hline $1.02(1.04$ to 1.14$)$ & .02 & $1.01(1.00$ to 1.02$)$ & .001 \\
\hline $1.26(1.14$ to 1.38$)$ & .002 & $1.03(1.01$ to 1.04$)$ & .001 \\
\hline $1.01(0.98$ to 1.04$)$ & .50 & $1.00(0.98$ to 1.02$)$ & .60 \\
\hline $1.05(1.03$ to 1.07$)$ & $<.001$ & $1.02(1.01$ to 1.02$)$ & $<.001$
\end{tabular}

NOTE. The PRR is presented for 5-year increase in duration.

Abbreviation: PRR, prevalence rate ratio.

${ }^{*}$ Frailty $\geq 3$ components.

†Prefrailty $\geq 2$ components.

$\ddagger$ The models were adjusted for sex, race, age at diagnosis and age at assessment.

TABLE A6. Assessment of Goodness of Fit for the Associations Between Treatment, Grade 3-4 Chronic Health Conditions, Lifestyle Factors, and Frailty

\begin{tabular}{|c|c|c|c|c|c|c|c|}
\hline Models & $\begin{array}{l}\text { Degrees of } \\
\text { Freedom* }\end{array}$ & $\chi^{2}$ & Log-Likelihood & AIC & BIC & $\begin{array}{c}-2 \\
\text { Log-Likelihood } \dagger\end{array}$ & $P \ddagger$ \\
\hline Null model§ & 30 & 10427.0951 & -2291.6260 & 4645.2520 & 4868.1652 & - & \\
\hline $\begin{array}{l}\text { Model with chronic health } \\
\text { conditions\|l }\end{array}$ & 27 & 10019.0127 & -2222.2335 & 4500.4670 & 4702.1175 & 138.785 & $<.01$ \\
\hline Model with lifestyle factors & 33 & 8779.9661 & -2035.4406 & 4138.8811 & 4383.0566 & 512.3708 & $<.01$ \\
\hline
\end{tabular}

NOTE. The analysis was adjusted for sex, race/ethnicity, age at diagnosis, and age at assessments.

Abbreviations: AIC, Akaike information criteria; BIC, Bayesian information criterion.

*Degrees of freedom are based on number of parameters.

$\dagger-2$ log-likelood: the difference between the log-likelihood of the null model and the model with chronic conditions, and the model with treatment exposures and lifestyle.

$\ddagger P$ value for the -2 log-likelihood. $P$ value is for the difference between the distribution of the two models.

$\S$ Null model: includes treatment exposures associated with frailty.

IIModel with chronic health conditions: includes treatment exposures and grade 3-4 cardiac, neurologic, respiratory, musculoskeletal, endocrine, renal, and all other conditions.

TModel with lifestyle factors: includes treatment exposures, cardiac, neurologic, respiratory, musculoskeletal, endocrine, renal, all other chronic conditions, sedentary behavior, obesity, and smoking. 
TABLE A7. Assessment of Goodness of Fit for the Associations Between Treatment, Grade 3-4 Chronic Health Conditions, and Lifestyle Factors and Prefrailty

\begin{tabular}{lccccccc} 
Models & $\begin{array}{c}\text { Degrees of } \\
\text { Freedom* }\end{array}$ & $\boldsymbol{\chi}^{\mathbf{2}}$ & Log-Likelihood & AIC & BIC & $\begin{array}{c}\mathbf{- 2} \\
\text { Log-Likelihood } \dagger\end{array}$ & $\boldsymbol{P} \ddagger$ \\
\hline Null modelई & 30 & 9383.6931 & -5027.0552 & 10116.11 & 10339.023 & - & - \\
\hline $\begin{array}{l}\text { Model with chronic health } \\
\text { conditionsll }\end{array}$ & 31 & 9059.229 & -4818.14 & 9700.295 & 9930.0153 & 417.8304 & $<.01$ \\
\hline Model with lifestyle factors & 37 & 8711.82 & -4617.21 & 9310.4174 & 9583.2098 & 819.6904 & $<.01$
\end{tabular}

Abbreviations: AIC, Akaike information criteria; BIC, Bayesian information criterion.

*Degrees of freedom are based on number of parameters.

$\dagger-2$ log-likelood: the difference between the log-likelihood of the null model and the model with chronic conditions, and the model with treatment exposures and lifestyle.

$\ddagger P$ value for the -2 log-likelihood. $P$ value is for the difference between the distribution of the two models.

$\S$ Null model: includes treatment exposures associated with frailty.

IIModel with chronic health conditions: includes treatment exposures and grade 3-4 cardiac, neurologic, respiratory, musculoskeletal, endocrine, renal, and all other conditions.

ףModel with lifestyle factors: includes treatment exposures, cardiac, neurologic, respiratory, musculoskeletal, endocrine, renal, all other chronic conditions, sedentary behavior, obesity, and smoking. 
TABLE A8. Multinomial Logistic Regression for the Association Between Treatment Exposures and Frailty Among Survivors

Prefrail $^{*} v$ Nonfrail

Frail $\dagger \boldsymbol{v}$ Nonfrail

Prefrail $(n=1,272)$

Frail $(n=681)$

\begin{tabular}{|c|c|c|c|c|}
\hline Treatment Exposures & Adjusted OR $\ddagger(95 \% \mathrm{Cl})$ & $P$ & Adjusted OR $\ddagger(95 \% \mathrm{CI})$ & $P$ \\
\hline \multicolumn{5}{|l|}{ Chest radiation } \\
\hline Yes & 1.07 (0.87 to 1.34$)$ & .60 & 1.22 (0.91 to 1.68$)$ & .24 \\
\hline No & Ref & & Ref & \\
\hline \multicolumn{5}{|l|}{ Cranial radiation } \\
\hline Yes & 1.60 (1.35 to 1.85$)$ & $<.001 \S$ & 2.40 (1.94 to 2.96$)$ & $<.001 \S$ \\
\hline No & Ref & & Ref & \\
\hline \multicolumn{5}{|c|}{ Abdominal radiation dose, Gyll } \\
\hline$<20$ & 0.92 (0.64 to 1.32$)$ & .55 & 1.02 (0.62 to 1.66$)$ & .94 \\
\hline $20-40$ & 1.01 (0.73 to 1.39$)$ & .88 & 1.30 (0.80 to 1.84$)$ & .26 \\
\hline$>40$ & 1.18 (0.70 to 2.02$)$ & .80 & 1.86 (1.04 to 3.33$)$ & .04 \\
\hline None & Ref & & Ref & \\
\hline \multicolumn{5}{|c|}{ Pelvic radiation dose, Gyll } \\
\hline$<34$ & 1.18 (0.86 to 1.64$)$ & .16 & 0.96 (0.63 to 1.48$)$ & .86 \\
\hline$\geq 34$ & $1.12(0.80$ to 1.60$)$ & .36 & 1.77 (1.18 to 2.64$)$ & $.006 \S$ \\
\hline None & Ref & & Ref & \\
\hline \multicolumn{5}{|l|}{ Cisplatin dose, $\mathrm{mg} / \mathrm{m}^{2}$} \\
\hline$<600$ & 1.68 (1.30 to 2.16$)$ & $<.001 \S$ & $1.02(0.70$ to 1.45$)$ & .92 \\
\hline$\geq 600$ & 1.05 (0.60 to 1.84$)$ & .85 & 2.01 (1.14 to 3.52 ) & .02 \\
\hline None & Ref & & Ref & \\
\hline \multicolumn{5}{|c|}{ Carboplatin dose, $\mathrm{mg} / \mathrm{m}^{2}$} \\
\hline$<2,500$ & 0.66 (0.36 to 1.24$)$ & .20 & 1.35 (0.72 to 2.53$)$ & .35 \\
\hline$\geq 2,500$ & 1.60 (0.98 to 3.45$)$ & .06 & 1.86 (0.99 to 3.45$)$ & .06 \\
\hline None & Ref & & Ref & \\
\hline \multicolumn{5}{|l|}{ Methotrexate } \\
\hline Yes & 0.96 (0.80 to 1.16$)$ & .63 & 0.75 (0.60 to 0.98$)$ & $.04 \S$ \\
\hline No & Ref & & Ref & \\
\hline \multicolumn{5}{|l|}{ Alkylating agents } \\
\hline Yes & 1.20 (1.02 to 1.40$)$ & $.03 \S$ & 1.16 (0.92 to 1.45$)$ & .20 \\
\hline No & Ref & & Ref & \\
\hline \multicolumn{5}{|l|}{ 6-mercaptopurine } \\
\hline Yes & 0.93 (0.75 to 1.15$)$ & .56 & 0.82 (0.61 to 1.12$)$ & .31 \\
\hline No & Ref & & Ref & \\
\hline \multicolumn{5}{|l|}{ 6-thiogauine } \\
\hline Yes & 0.87 (0.68 to 1.10$)$ & .25 & 1.04 (0.80 to 1.44$)$ & .80 \\
\hline No & Ref & & Ref & \\
\hline \multicolumn{5}{|l|}{ Vinca alkaloids } \\
\hline Yes & 0.91 (0.77 to 1.07 ) & .26 & 0.85 (0.68 to 1.07$)$ & .19 \\
\hline No & Ref & & Ref & \\
\hline \multicolumn{5}{|l|}{ Anthracycline } \\
\hline Yes & 0.80 (0.70 to 0.94$)$ & $.03 \S$ & 0.90 (0.71 to 1.12$)$ & .65 \\
\hline No & Ref & & Ref & \\
\hline
\end{tabular}


TABLE A8. Multinomial Logistic Regression for the Association Between Treatment Exposures and Frailty Among Survivors (continued)

Prefrail $^{*} v$ Nonfrail

Prefrail $(n=1,272)$
Frailt $v$ Nonfrail

Frail $(n=681)$

\begin{tabular}{|c|c|c|c|c|}
\hline Treatment Exposures & Adjusted OR $\ddagger(95 \% \mathrm{CI})$ & $P$ & Adjusted OR $\ddagger(95 \% \mathrm{Cl})$ & $P$ \\
\hline \multicolumn{5}{|l|}{ Amputation } \\
\hline Yes & $1.58(1.14$ to 2.20$)$ & $.006 \S$ & 2.00 (1.32 to 3.00$)$ & $.001 \S$ \\
\hline No & Ref & & Ref & \\
\hline \multicolumn{5}{|l|}{ Lung surgery } \\
\hline No & Ref & & Ref & \\
\hline \multicolumn{5}{|l|}{ Spleen removal } \\
\hline Yes & $1.36(1.02$ to 1.80$)$ & $.03 \S$ & $0.95(0.65$ to 1.40$)$ & .80 \\
\hline No & Ref & & Ref & \\
\hline
\end{tabular}

Abbreviations: OR, odds ratio; Ref, reference.

*Prefrailty $=2$ components.

$\dagger$ Frailty $\geq 3$ components.

$\ddagger$ The model was adjusted for sex, race, age at diagnosis, and age at assessment.

IIRadiation dose: maximum tumor dose was determined by summing the prescribed dose to all overlapping fields within each respective region.

§Indicates estimates with a false discovery rate $<10$. 
TABLE A9. Multinomial Logistic Regression for the Association Between Sociodemographic Characteristics, Lifestyle, and Frailty Among Survivors

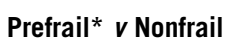

Prefrail $(n=1,272)$

Treatment Exposures

Sex

$\begin{array}{lc}\text { Female } & 1.43(1.27 \text { to } 1.61) \\ \text { Male } & \text { Ref } \\ \text { Race/ethnicity } & \end{array}$

Race/ethnicity

\begin{tabular}{|c|c|c|c|c|}
\hline Non-Hispanic black & 1.52 (1.17 to 1.97 ) & $.002 \S$ & 2.03 (1.47 to 2.78 ) & $<.001 \S$ \\
\hline Hispanic & 1.20 (0.94 to 1.52$)$ & .13 & 1.80 (1.35 to 2.40$)$ & $<.001 \S$ \\
\hline Others & 1.17 (0.87 to 1.58$)$ & .31 & $1.02(0.65$ to 1.60$)$ & .93 \\
\hline Non-Hispanic white & Ref & & Ref & \\
\hline \multicolumn{5}{|l|}{ Age at diagnosis, years } \\
\hline $0-4$ & 0.83 (0.70 to 1.01$)$ & .07 & $0.63(0.47$ to 0.81$)$ & $<.001 \S$ \\
\hline $5-10$ & 0.80 (0.61 to 1.03$)$ & .09 & 1.08 (0.90 to 1.30$)$ & .08 \\
\hline $10-14$ & 0.84 (0.70 to 1.03 ) & .44 & 0.80 (0.61 to 1.03$)$ & .66 \\
\hline$\geq 15$ & Ref & & Ref & \\
\hline
\end{tabular}

Age at assessment, years

\begin{tabular}{|c|c|c|c|c|}
\hline $18-29$ & Ref & & Ref & \\
\hline 30-39 & 1.07 (0.91 to 1.27$)$ & .41 & 1.20 (0.93 to 1.54$)$ & .16 \\
\hline $40-49$ & 1.05 (0.86 to 1.27$)$ & .63 & 1.26 (0.95 to 1.67 ) & .10 \\
\hline$\geq 50$ & 1.04 (0.80 to 1.34$)$ & .80 & 1.38 (0.97 to 1.96 ) & .07 \\
\hline \multicolumn{5}{|c|}{ Smoking statusll } \\
\hline Current & 1.43 (1.24 to 1.65$)$ & $<.001 \S$ & 1.42 (1.12 to 1.73$)$ & $<.001 \S$ \\
\hline Former & $1.01(0.85$ to 1.21$)$ & .90 & 0.96 (0.75 to 1.22$)$ & .74 \\
\hline Never & Ref & & Ref & \\
\hline \multicolumn{5}{|c|}{ Sedentary behavior $\mathbb{T}$} \\
\hline Current & 3.06 (2.68 to 3.50 ) & $<.001 \S$ & 6.33 (5.3 to 7.57 ) & $<.001 \S$ \\
\hline Former & 1.83 (1.53 to 2.18$)$ & $<.001 \S$ & 2.73 (2.14 to 3.50 ) & $<.001 \S$ \\
\hline Never & Ref & & Ref & \\
\hline \multicolumn{5}{|c|}{ Obesity (BMI $\geq 30$ kg) } \\
\hline Current & 1.58 (1.39 to 1.80$)$ & $<.001 \S$ & $1.62(1.36$ to 1.93$)$ & $<.001 \S$ \\
\hline Former & 1.52 (1.10 to 2.10 ) & $.01 \S$ & 1.50 (0.98 to 2.28$)$ & .06 \\
\hline Never & Ref & & Ref & \\
\hline
\end{tabular}

Abbreviations: BMI, body mass index; OR, odds ratio; Ref, reference.

${ }^{*}$ Prefrailty $=2$ components.

†Frailty $\geq 3$ components.

§Indicates estimates with a false discovery rate $<10$.

IISmoking status was defined as those who reported $\geq 100$ cigarettes in their lifetime and smoking in the past month; 35 participants did not report their smoking status.

ISedentary behavior: persons who responded no to the question: "During the past month, did you participate in any physical activities such as running, aerobic, golf, gardening, bicycling, swimming, wheelchair basketball, or walking for exercise?"

Frail $\dagger v$ Nonfrail

Frail $(n=681)$

Adjusted OR (95\% Cl)

$1.44(1.22$ to 1.68$)<.001 \S$

Ref 
TABLE A10. Multinomial Logistic Regression for the Association Between Grade 3-4 Chronic Health Conditions and Frailty Among Survivors

Prefrail $^{*} v$ Nonfrail

Prefrail $(n=1,272)$
Frail $\dagger \boldsymbol{v}$ Nonfrail

Frail $(n=681)$

\begin{tabular}{|c|c|c|c|c|}
\hline \multirow{2}{*}{ Grade 3-4 Chronic Health Conditions } & & & \multirow[b]{2}{*}{ Adjusted OR $\ddagger(95 \% \mathrm{CI})$} & \multirow[b]{2}{*}{$P$} \\
\hline & Adjusted OR $\ddagger(95 \% \mathrm{CI})$ & $P$ & & \\
\hline \multicolumn{5}{|l|}{ Any chronic condition§ } \\
\hline Yes & 2.23 (2.04 to 2.60 ) & $<.001 \|$ & 3.75 (3.21 to 4.40 ) & $<.001 \|$ \\
\hline No & Ref & & Ref & \\
\hline \multicolumn{5}{|l|}{ Cardiac } \\
\hline Yes & 1.54 (1.23 to 1.93 ) & $<.001 \|$ & 2.46 (1.92 to 3.15 ) & $<.001 \|$ \\
\hline No & Ref & & Ref & \\
\hline \multicolumn{5}{|l|}{ SMN } \\
\hline Yes & 1.26 (0.97 to 1.64$)$ & .08 & 1.36 (1.00 to 1.88 ) & $.04 \|$ \\
\hline No & Ref & & Ref & \\
\hline \multicolumn{5}{|l|}{ Neurologic } \\
\hline Yes & 3.57 (2.88 to 4.44$)$ & $<.001$ & 7.12 (5.61 to 9.05$)$ & $<.001$ \\
\hline No & Ref & & Ref & \\
\hline \multicolumn{5}{|l|}{ Musculoskeletal } \\
\hline Yes & 1.78 (1.42 to 2.24$)$ & $<.001 \|$ & 2.11 (1.60 to 2.80$)$ & $<.001 \|$ \\
\hline No & Ref & & Ref & \\
\hline \multicolumn{5}{|l|}{ Endocrine } \\
\hline Yes & 1.26 (1.01 to 1.56$)$ & $.03 \|$ & $1.80(1.40$ to 2.31$)$ & $<.001 \|$ \\
\hline No & Ref & & Ref & \\
\hline \multicolumn{5}{|l|}{ Respiratory } \\
\hline Yes & 1.49 (0.70 to 3.05$)$ & .30 & 4.83 (2.67 to 3.71$)$ & $<.001 \|$ \\
\hline No & Ref & & Ref & \\
\hline \multicolumn{5}{|l|}{ Renal } \\
\hline Yes & $1.41(0.80$ to 2.50$)$ & .22 & $1.48(0.72$ to 3.04$)$ & .25 \\
\hline No & Ref & & Ref & \\
\hline \multicolumn{5}{|l|}{ Other chronic conditions } \\
\hline Yes & 1.83 (1.57 to 2.15 ) & $<.001 \|$ & 1.90 (1.53 to 2.31$)$ & $.001 \|$ \\
\hline No & Ref & & Ref & \\
\hline
\end{tabular}

Abbreviations: OR, odds ratio; Ref, reference; SMN, second malignant neoplasm.

*Prefrailty $=2$ components.

$\dagger$ Frailty $\geq 3$ components.

$\ddagger$ The model was adjusted for sex, race, age at diagnosis, age at assessment.

$\S$ Any chronic condition was conducted in separate model, and the prevalence rate ratio $(95 \% \mathrm{Cl})$ was reported in the table.

IIIndicates estimates with a false discovery rate $<10$. 
TABLE A11. Multinomial Logistic Regression for the Association Between Treatment Exposure, Grade 3-4 Chronic Conditions, and Frailty

Prefrail $^{*} v$ Nonfrail

Prefrail $(n=1,272)$
Frail $\dagger v$ Nonfrail

Frail $(n=681)$

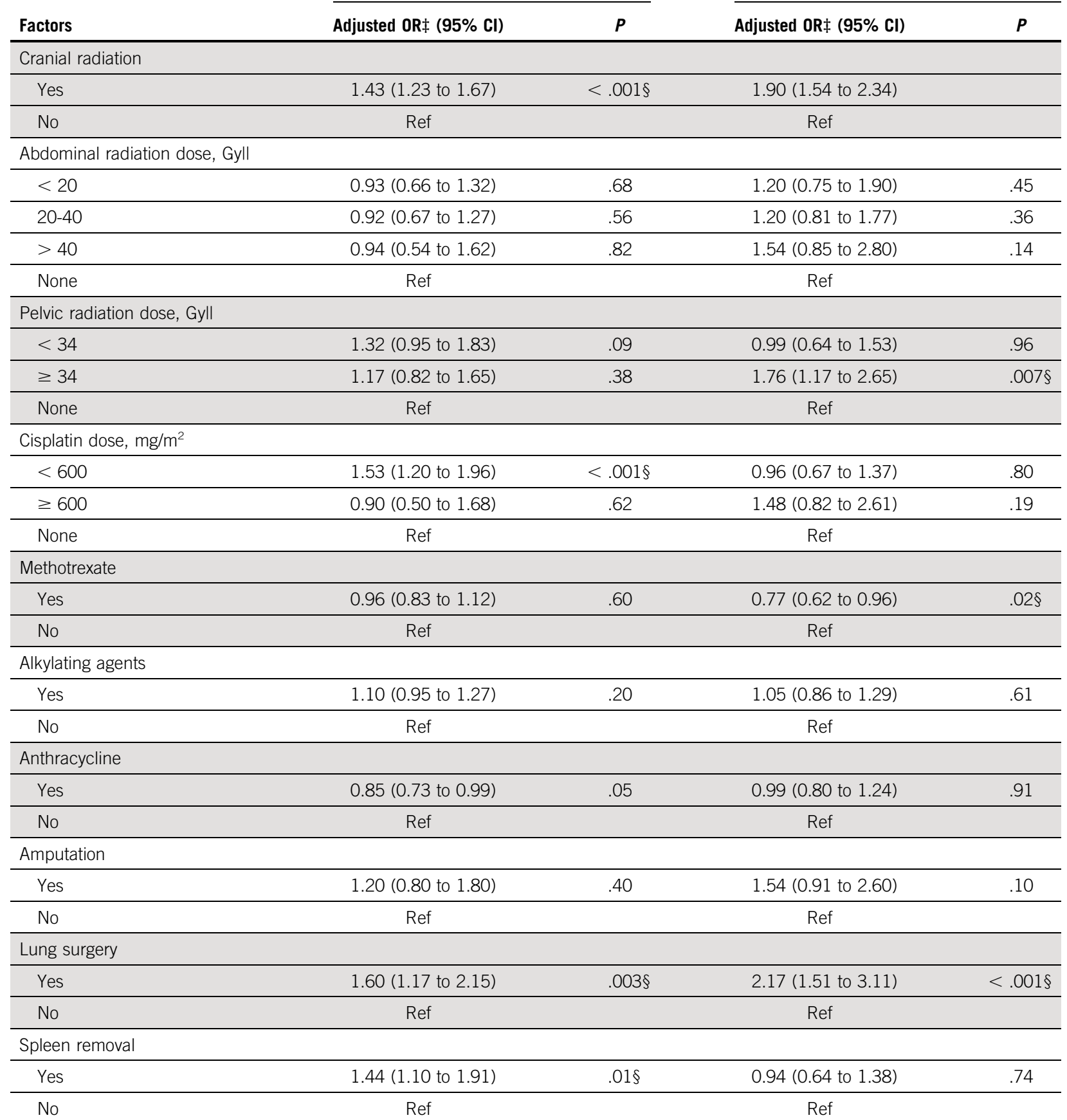

Abbreviations: OR, odds ratio; Ref, reference.

*Prefrailty $=2$ components.

$\dagger$ Frailty $\geq 3$ components.

$\ddagger$ The model includes treatments that were significant in first model (Table A8). The model was adjusted for sex, race, age at diagnosis, age at assessment, and grade 3-4 chronic health condition.

§Indicates estimates with a false discovery rate $<10$.

IIRadiation dose: maximum tumor dose was determined by summing the prescribed dose to all overlapping fields within each respective region. 
TABLE A12. Multinomial Logistic Regression for the Association Between Treatment Exposure, Grade 3-4 Chronic Conditions, Lifestyle Factors, and Frailty

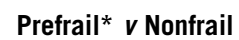

Prefrail $(n=1,272)$

\section{Factors}

Sex

Female

Male

Race/ethnicity

\begin{tabular}{lc}
\hline Non-Hispanic black & $1.72(1.30$ to 2.30$)$ \\
\hline Hispanic & $1.10(0.83$ to 1.43$)$ \\
\hline Others & $1.08(0.77$ to 1.53$)$ \\
\hline Non-Hispanic white & Ref \\
\hline Age at diagnosis, years & $0.87(0.70$ to 1.10$)$ \\
\hline $0-4$ & $1.02(0.82$ to 1.26$)$ \\
\hline $5-10$ & $0.83(0.65$ to 1.05$)$ \\
\hline $10-14$ & Ref \\
\hline$\geq 15$ &
\end{tabular}

Age at assessment, years

\begin{tabular}{|c|c|c|c|c|}
\hline $18-29$ & Ref & & Ref & \\
\hline 30-39 & 1.01 (0.84 to 1.22$)$ & .87 & 1.01 (0.76 to 1.34$)$ & .95 \\
\hline $40-49$ & 0.95 (0.76 to 1.20$)$ & .70 & $0.99(0.72$ to 1.40$)$ & .99 \\
\hline$\geq 50$ & 0.83 (0.61 to 1.13$)$ & .24 & 1.01 (0.66 to 1.55$)$ & .95 \\
\hline \multicolumn{5}{|c|}{ Cranial radiation } \\
\hline Yes & 1.28 (1.10 to 1.50$)$ & $.002 \S$ & 1.72 (1.38 to 2.15$)$ & $<.001 \S$ \\
\hline No & Ref & & Ref & \\
\hline \multicolumn{5}{|c|}{ Abdominal radiation dose, Gy\| } \\
\hline$<20$ & 1.04 (0.73 to 1.48$)$ & .89 & 1.39 (0.90 to 2.23$)$ & .17 \\
\hline $20-40$ & $0.96(0.71$ to 1.31$)$ & .81 & $1.26(0.84$ to 1.89$)$ & .26 \\
\hline$>40$ & 1.06 (0.61 to 1.86$)$ & .83 & 1.63 (0.88 to 3.04$)$ & .12 \\
\hline None & Ref & & Ref & \\
\hline \multicolumn{5}{|c|}{ Pelvic radiation dose, Gy\| } \\
\hline$<34$ & 1.32 (0.95 to 1.83$)$ & .16 & 0.99 (0.64 to 1.53$)$ & .92 \\
\hline$\geq 34$ & $1.17(0.82$ to 1.65$)$ & .45 & 1.76 (1.17 to 2.65$)$ & $.007 \S$ \\
\hline None & Ref & & Ref & \\
\hline \multicolumn{5}{|c|}{ Cisplatin dose, $\mathrm{mg} / \mathrm{m}^{2}$} \\
\hline$<600$ & 1.56 (1.20 to 2.02 ) & $<.001 \S$ & 0.98 (0.67 to 1.44$)$ & .93 \\
\hline$\geq 600$ & $0.81(0.50$ to 1.45$)$ & .48 & $1.36(0.74$ to 2.51$)$ & .32 \\
\hline None & Ref & & Ref & \\
\hline \multicolumn{5}{|c|}{ Methotrexate } \\
\hline Yes & 0.92 (0.80 to 1.07$)$ & .28 & $0.74(0.60$ to 0.92$)$ & $.007 \S$ \\
\hline No & Ref & & Ref & \\
\hline \multicolumn{5}{|c|}{ Alkylating agents } \\
\hline Yes & 1.17 (1.01 to 1.36$)$ & $.03 \S$ & $1.14(0.92$ to 1.40$)$ & .23 \\
\hline No & Ref & & Ref & \\
\hline
\end{tabular}

Frail $\dagger v$ Nonfrail

Frail $(n=681)$

\section{Adjusted OR $¥(95 \% \mathrm{Cl})$}

1.47 (1.30 to 1.68$)$

Ref

$<.001 \S$

$.001 \S$

.54

.65

.25

.88

.11

$P$

65

0.70 (0.50 to 0.94$)$

0.94 (0.71 to 1.24)

0.55 (0.40 to 0.76$)$

Ref

Ref

\section{Adjusted OR $(95 \% \mathrm{Cl})$}

1.50 (1.24 to 1.81$)$

2.20 (1.51 to 3.21)

$<.001 \S$

$<.001 \S$

0.98 (0.60 to 1.66$)$

.94

1.99 (1.44 to 2.76 ) 
TABLE A12. Multinomial Logistic Regression for the Association Between Treatment Exposure, Grade 3-4 Chronic Conditions, Lifestyle Factors, and Frailty (continued)

Prefrail $^{*} v$ Nonfrail

Prefrail $(n=1,272)$

\section{Factors}

Anthracycline

Yes

No

Amputation

\begin{tabular}{|c|c|c|c|c|}
\hline Yes & $1.18(0.77$ to 1.81$)$ & .43 & 1.54 (0.91 to 2.60$)$ & .11 \\
\hline No & Ref & & Ref & \\
\hline \multicolumn{5}{|c|}{ Lung surgery } \\
\hline Yes & 1.64 (1.20 to 2.24$)$ & $.002 \S$ & 2.25 (1.54 to 3.29$)$ & $<.001 \S$ \\
\hline No & Ref & & Ref & \\
\hline \multicolumn{5}{|c|}{ Spleen removal } \\
\hline Yes & 1.57 (1.18 to 2.10 ) & $.002 \S$ & $1.10(0.73$ to 1.62$)$ & .68 \\
\hline No & Ref & & Ref & \\
\hline \multicolumn{5}{|l|}{ Cardiac } \\
\hline Yes & 1.37 (1.06 to 1.78 ) & $.01 \S$ & 2.00 (1.50 to 2.68$)$ & $<.001 \S$ \\
\hline No & Ref & & Ref & \\
\hline \multicolumn{5}{|l|}{ Neurologic } \\
\hline Yes & 3.44 (2.70 to 4.40$)$ & $<.001 \S$ & 6.17 (4.65 to 8.20$)$ & $<.001 \S$ \\
\hline No & Ref & & Ref & \\
\hline \multicolumn{5}{|c|}{ Musculoskeletal } \\
\hline Yes & 1.48 (1.03 to 2.13 ) & $.03 \S$ & 1.35 (0.83 to 2.19) & .22 \\
\hline No & Ref & & & \\
\hline \multicolumn{5}{|l|}{ Endocrine } \\
\hline Yes & 1.20 (0.93 to 1.53$)$ & .16 & 1.63 (1.21 to 2.11$)$ & $.001 \S$ \\
\hline No & Ref & & Ref & \\
\hline \multicolumn{5}{|l|}{ Respiratory } \\
\hline Yes & 0.99 (0.41 to 2.38) & .97 & 3.41 (1.64 to 7.10$)$ & $.001 \S$ \\
\hline No & Ref & & Ref & \\
\hline \multicolumn{5}{|l|}{ SMN } \\
\hline Yes & 0.99 (0.73 to 1.36$)$ & .99 & $1.10(0.73$ to 1.56$)$ & .74 \\
\hline No & Ref & & Ref & \\
\hline \multicolumn{5}{|c|}{ Other chronic conditions } \\
\hline Yes & 1.47 (1.22 to 1.78 ) & $<.001 \S$ & 1.56 (1.21 to 1.99 ) & $<.001 \S$ \\
\hline No & Ref & & Ref & \\
\hline \multicolumn{5}{|c|}{ Smoking status $\|$} \\
\hline Current & 1.60 (1.40 to 1.87$)$ & $<.001 \S$ & 1.74 (1.39 to 2.18 ) & $<.001 \S$ \\
\hline Former & 1.10 (0.90 to 1.33$)$ & .40 & $1.10(0.80$ to 1.41$)$ & .67 \\
\hline Never & Ref & & Ref & \\
\hline \multicolumn{5}{|c|}{ Sedentary behavior } \\
\hline Current & 3.0 (2.60 to 3.47$)$ & $<.001 \S$ & 5.19 (4.23 to 6.35$)$ & $<.001 \S$ \\
\hline Former & 1.74 (1.43 to 2.13$)$ & $<.001 \S$ & 2.35 (1.80 to 3.11$)$ & $<.001 \S$ \\
\hline Never & Ref & & Ref & \\
\hline \multicolumn{5}{|c|}{ (continued on following page) } \\
\hline
\end{tabular}

Frail $\dagger v$ Nonfrail

Frail $(n=681)$

\section{Adjusted OR $\ddagger(95 \% \mathrm{CI})$}

0.87 (0.73 to 1.02$)$

.09

1.06 (0.84 to 1.34$)$

64

Ref

Ref

\section{Adjusted OR $\ddagger(95 \% \mathrm{Cl})$}

\section{$\boldsymbol{P}$}

Ref


TABLE A12. Multinomial Logistic Regression for the Association Between Treatment Exposure, Grade 3-4 Chronic Conditions, Lifestyle Factors, and Frailty (continued)

Prefrail $^{*} v$ Nonfrail

Prefrail $(n=1,272)$
Frail $\dagger v$ Nonfrail

Frail $(n=681)$

\begin{tabular}{|c|c|c|c|c|}
\hline Factors & Adjusted OR $\ddagger(95 \% \mathrm{CI})$ & $P$ & Adjusted OR $\ddagger(95 \% \mathrm{CI})$ & $P$ \\
\hline \multicolumn{5}{|c|}{ Obesity $\left(\mathrm{BMI} \geq 30 \mathrm{~kg} / \mathrm{m}^{2}\right) \#$} \\
\hline Current & 1.73 (1.50 to 1.99$)$ & $<.001 \S$ & 1.74 (1.43 to 2.13$)$ & $<.001 \S$ \\
\hline Former & 1.30 (0.90 to 1.92$)$ & .18 & 1.40 (0.85 to 2.29$)$ & .18 \\
\hline Never & Ref & & Ref & \\
\hline
\end{tabular}

Abbreviations: BMI, body mass index; OR, odds ratio; Ref, reference; SMN, second malignant neoplasm.

*Prefrailty $=2$ components.

†Frailty $\geq 3$ components.

$\ddagger$ The model includes treatments that were significant in first model (Table A8). The model was adjusted for sex, race, age at diagnosis, age at assessment, and grade 3-4 chronic health condition.

§Indicates estimates with a false discovery rate $<10$.

||Radiation dose: maximum tumor dose was determined by summing the prescribed dose to all overlapping fields within each respective region. 
TABLE A13. Associations Between Treatment Exposures and Frailty Among Childhood Cancer Participants (survivors and deceased participants) ${ }^{1}$

Frailty $(n=4,050)^{*}$

\begin{tabular}{|c|c|c|c|c|}
\hline Treatment Exposures & Participants ( $n=14,268)$ & Row (\%)† & Adjusted PRR $\ddagger(95 \% \mathrm{Cl})$ & $P$ \\
\hline \multicolumn{5}{|l|}{ Chest radiation } \\
\hline Yes & 3,664 & 39.5 & 1.20 (0.91 to 1.58$)$ & .19 \\
\hline No & 9,716 & 20.7 & Ref & \\
\hline \multicolumn{5}{|l|}{ Cranial radiation } \\
\hline Yes & 4,034 & 33.6 & 2.06 (1.70 to 2.51$)$ & $<.001 \S$ \\
\hline No & 9,346 & 22.0 & Ref & \\
\hline \multicolumn{5}{|c|}{ Abdominal radiation dose, Gyll } \\
\hline$<20$ & 1,195 & 28.6 & $0.98(0.62$ to 1.56$)$ & .96 \\
\hline $20-41$ & 1,827 & 42.5 & $1.15(0.77$ to 1.71$)$ & .47 \\
\hline$\geq 41$ & 362 & 56.9 & 1.60 (0.94 to 2.73$)$ & .08 \\
\hline None & 9,996 & 21.4 & Ref & \\
\hline \multicolumn{5}{|c|}{ Pelvic radiation dose, Gyll } \\
\hline$<34$ & 1,716 & 32.8 & 0.93 (0.62 to 1.34$)$ & .81 \\
\hline$\geq 34$ & 1,141 & 52.0 & 1.84 (1.10 to 3.10$)$ & $.02 \S$ \\
\hline None & 10,523 & 21.8 & Ref & \\
\hline \multicolumn{5}{|l|}{ Cisplatin dose, $\mathrm{mg} / \mathrm{m}^{2}$} \\
\hline$<600$ & 911 & 33.6 & 0.96 (0.68 to 1.04$)$ & .09 \\
\hline$\geq 600$ & 212 & 40.1 & 1.52 (1.08 to 2.15$)$ & $.02 \S$ \\
\hline None & 11,789 & 23.9 & Ref & \\
\hline \multicolumn{5}{|c|}{ Carboplatin dose, $\mathrm{mg} / \mathrm{m}^{2}$} \\
\hline$<2,500$ & 198 & 36.6 & $1.27(0.71$ to 2.24$)$ & .42 \\
\hline$\geq 2,500$ & 202 & 31.3 & 1.48 (0.84 to 2.60$)$ & .17 \\
\hline None & 12,639 & 24.6 & Ref & \\
\hline \multicolumn{5}{|l|}{ Methotrexate } \\
\hline Yes & 4,921 & 19.4 & 0.77 (0.60 to 1.00$)$ & .05 \\
\hline No & 8,169 & 29.3 & Ref & \\
\hline \multicolumn{5}{|l|}{ Alkylating agents } \\
\hline Yes & 7,288 & 28.3 & 1.11 (0.90 to 1.38$)$ & .30 \\
\hline No & 6,010 & 21.6 & Ref & \\
\hline \multicolumn{5}{|l|}{ 6-mercaptopurine } \\
\hline Yes & 2,670 & 13.8 & 0.85 (0.64 to 1.15$)$ & .29 \\
\hline No & 10,420 & 29.2 & Ref & \\
\hline \multicolumn{5}{|l|}{ 6-thiogauine } \\
\hline Yes & 1,128 & 14.8 & $1.04(0.76$ to 1.41$)$ & .82 \\
\hline No & 11,962 & 26.1 & Ref & \\
\hline \multicolumn{5}{|l|}{ Vinca alkaloids } \\
\hline Yes & 8,319 & 20.1 & $0.88(0.71$ to 1.10$)$ & .26 \\
\hline No & 4,771 & 34.8 & Ref & \\
\hline \multicolumn{5}{|l|}{ Anthracycline } \\
\hline Yes & 6,232 & 22.9 & $0.96(0.77$ to 1.20$)$ & .74 \\
\hline No & 7,082 & 27.9 & Ref & \\
\hline
\end{tabular}


TABLE A13. Associations Between Treatment Exposures and Frailty Among Childhood Cancer Participants (survivors and deceased participants) ${ }^{1}$ (continued)

Frailty $(n=4,050)^{*}$

Treatment Exposures

Participants $(n=14,268)$

Row (\%) $\dagger \quad$ Adjusted PRR $\quad(95 \% \mathrm{Cl})$

$\boldsymbol{P}$

\begin{tabular}{|c|c|c|c|c|}
\hline \multicolumn{5}{|c|}{ Amputation } \\
\hline Yes & 583 & 33.0 & 1.74 (1.18 to 2.53$)$ & $.004 \S$ \\
\hline No & 12,936 & 22.1 & Ref & \\
\hline \multicolumn{5}{|c|}{ Lung surgery } \\
\hline Yes & 184 & 34.7 & 2.08 (1.52 to 2.85$)$ & $<.001 \S$ \\
\hline No & 3,137 & 22.2 & Ref & \\
\hline \multicolumn{5}{|c|}{ Spleen removal } \\
\hline Yes & 753 & 8.0 & 0.93 (0.65 to 1.34$)$ & .70 \\
\hline No & 12,747 & 23.4 & Ref & \\
\hline
\end{tabular}

NOTE. The analysis includes survivors and deceased participants; deceased participants were considered as frail.

Abbreviations: PRR, prevalence rate ratio; Ref, reference.

${ }^{*}$ Frailty $\geq 3$ components.

tWeighted row percentages are presented.

$\ddagger$ The model was adjusted for sex, race, age at diagnosis, and age at assessment.

$\S$ Indicates estimates with a false discovery rate $<10 \%$.

IIRadiation dose: maximum tumor dose was determined by summing the prescribed dose to all overlapping fields within each respective region. 
TABLE A14. Associations Between Sociodemographic Characteristics, Lifestyle, and Frailty Among Childhood Cancer Participants (survivors and deceased participants)

Frailty $(n=4,050)$ *

\begin{tabular}{|c|c|c|c|c|}
\hline Factors & Participants $(n=14,268)$ & Row $(\%) \dagger$ & Adjusted PRR (95\% Cl) & $P$ \\
\hline \multicolumn{5}{|l|}{ Sex } \\
\hline Female & 7,109 & 24.0 & 1.02 (0.97 to 1.15$)$ & .19 \\
\hline Male & 7,159 & 29.0 & Ref & \\
\hline \multicolumn{5}{|l|}{ Race/ethnicity } \\
\hline Non-Hispanic black & 682 & 38.2 & 1.11 (0.96 to 1.27$)$ & .16 \\
\hline Hispanic & 869 & 28.4 & 1.11 (0.96 to 1.29$)$ & .14 \\
\hline Others & 495 & 3.1 & 0.90 (0.74 to 1.08$)$ & .25 \\
\hline Non-Hispanic white & 12,219 & 25.9 & Ref & \\
\hline \multicolumn{5}{|l|}{ Age at diagnosis, years } \\
\hline $0-4$ & 3,549 & 20.1 & $0.80(0.73$ to 0.87$)$ & $<.001 \ddagger$ \\
\hline $5-9$ & 3,546 & 24.1 & 0.96 (0.88 to 1.03 ) & .26 \\
\hline $10-14$ & 3,088 & 30.1 & 1.10 (1.02 to 1.170$)$ & $.02 \ddagger$ \\
\hline$\geq 15$ & 4,079 & 35.2 & Ref & \\
\hline \multicolumn{5}{|c|}{ Age at assessment, years } \\
\hline$<30$ & 4,053 & 42.5 & Ref & \\
\hline 30-39 & 4,912 & 17.8 & 1.07 (0.99 to 1.14 & .06 \\
\hline $40-49$ & 3,674 & 20.0 & 0.90 (0.84 to 0.96$)$ & $.004 \ddagger$ \\
\hline$\geq 50$ & 1,629 & 21.0 & $0.82(0.74$ to 0.90$)$ & $<.001 \ddagger$ \\
\hline \multicolumn{5}{|l|}{ Smoking status\|l } \\
\hline Current & 1,904 & 7.9 & 0.92 (0.77 to 1.09 ) & .33 \\
\hline Former & 2,153 & 34.1 & 1.07 (0.99 to 1.18$)$ & .07 \\
\hline Never & 9,356 & 22.0 & Ref & \\
\hline \multicolumn{5}{|l|}{ Sedentary behavior $\mathbb{T}$} \\
\hline Current & 2,135 & 14.8 & 1.54 (1.40 to 1.68$)$ & $<.001 \ddagger$ \\
\hline Former & 3,016 & 52.7 & 2.02 (1.85 to 2.21$)$ & $<.001 \ddagger$ \\
\hline Never & 7,214 & 2.9 & Ref & \\
\hline \multicolumn{5}{|c|}{ Obesity (BMI $\geq 30 \mathrm{~kg} / \mathrm{m}^{2}$ ) } \\
\hline Current & 2,572 & 8.7 & 0.6 (0.66 to 0.72$)$ & $<.001 \ddagger$ \\
\hline Former & 2,752 & 90.1 & 2.89 (2.26 to 3.11$)$ & $<.001 \ddagger$ \\
\hline Never & 8,286 & 10.6 & Ref & \\
\hline
\end{tabular}

NOTE. The analysis includes survivors and deceased participants; deceased participants were considered as frail.

Abbreviations: BMI, body mass index; PRR, prevalence rate ratio; Ref, reference.

${ }^{*}$ Frailty $\geq 3$ components.

†Weighted row percentages.

łIndicates estimates with a false discovery rate $<10 \%$.

IISmoking status was defined as those who reported $\geq 100$ cigarettes in their lifetime and smoking in the past month. The mean (standard deviation) for number of cigarettes per day was calculated among those who reported current or former smoker.

ISedentary behavior: persons who responded no to the question: "During the past month, did you participate in any physical activities such as running, aerobic, golf, gardening, bicycling, swimming, wheelchair basketball, or walking for exercise?" 
TABLE A15. Associations Between Grade 3-4 Chronic Health Conditions and Frailty Among Childhood Cancer Participants (survivors and deceased participants)

Frailty $(n=4,050)^{*}$

\begin{tabular}{|c|c|c|c|c|}
\hline Grade 3-4 Chronic Health Conditions & Participants $(n=14,268)$ & Row (\%) $\dagger$ & Adjusted PRR $\ddagger(95 \% \mathrm{Cl})$ & $P$ \\
\hline Any chronic condition§ & 4,983 & 39.2 & & \\
\hline Yes & 9,285 & 20.4 & 1.70 (1.57 to 1.83 ) & $<.001 \|$ \\
\hline No & & & Ref & \\
\hline Cardiac & 1,018 & 51.6 & & \\
\hline Yes & 13,250 & 24.8 & 1.37 (1.23 to 1.53$)$ & $<.001 \|$ \\
\hline No & & & Ref & \\
\hline SMN & 671 & 34.8 & & \\
\hline Yes & 13,597 & 26.2 & $1.14(0.99$ to 1.31$)$ & .06 \\
\hline No & & & Ref & \\
\hline Neurologic & 878 & 51.5 & & \\
\hline Yes & 13,390 & 25.0 & 2.02 (1.81 to 2.22$)$ & $<.001 \|$ \\
\hline No & & & Ref & \\
\hline Musculoskeletal & 838 & 36.6 & & \\
\hline Yes & 13,430 & 26.0 & $1.32(1.16$ to 1.50$)$ & $<.001 \|$ \\
\hline No & & & Ref & \\
\hline Endocrine & 1,098 & 35.8 & & \\
\hline Yes & 13,170 & 25.9 & 1.27 (1.13 to 1.43$)$ & $<.001 \|$ \\
\hline No & & & Ref & \\
\hline Respiratory & 166 & 74.5 & & \\
\hline Yes & 14,102 & 26.0 & 1.79 (1.43 to 2.23 ) & $<.001$ \\
\hline No & & & Ref & \\
\hline Renal & 189 & 59.8 & & \\
\hline Yes & 14,079 & 23.3 & 1.18 (0.85 to 1.62$)$ & .32 \\
\hline No & & & Ref & \\
\hline Other chronic conditions & 1,986 & 38.9 & & \\
\hline Yes & 12,282 & 24.7 & $1.28(1.16$ to 1.40$)$ & $<.001 \|$ \\
\hline No & & & Ref & \\
\hline
\end{tabular}

NOTE. The analysis includes survivors and deceased participants, deceased participants were considered as frail.

Abbreviations: PRR, prevalence rate ratio; Ref, reference; SMN, second malignant neoplasm.

${ }^{\star}$ Frailty $\geq 3$ components.

tWeighted row percentages.

$\ddagger$ The model was adjusted for sex, race, age at diagnosis, and age at assessment.

§Any chronic condition was conducted in separate model, and the PRR $(95 \% \mathrm{Cl})$ was reported in the table.

IIIndicates estimates with a false discovery rate $<10 \%$. 
TABLE A16. Associations Between Treatment Exposures, Grade 3-4 Chronic Conditions, Lifestyle Factors, and Frailty Among Childhood Cancer Participants (survivors and deceased participants)

Frailty* $(n=4,050)$

\begin{tabular}{|c|c|c|c|c|}
\hline \multirow{2}{*}{ Factors } & & & & \\
\hline & Adjusted PRR $\dagger(95 \% \mathrm{CI})$ & $P$ & Adjusted PRR $\ddagger(95 \% \mathrm{Cl})$ & $P$ \\
\hline \multicolumn{5}{|c|}{ Cranial radiation } \\
\hline Yes & 1.31 (1.20 to 1.44$)$ & $<.001 \S$ & 1.22 (1.10 to 1.35$)$ & $<.001 \S$ \\
\hline No & Ref & & Ref & \\
\hline \multicolumn{5}{|c|}{ Abdominal radiation dose, Gyll } \\
\hline$<20$ & 1.003 (0.75 to 1.35$)$ & .98 & 1.06 (0.80 to 1.43$)$ & .67 \\
\hline $20-41$ & 0.99 (0.80 to 1.23$)$ & .97 & $0.98(0.80$ to 1.21$)$ & .87 \\
\hline$\geq 41$ & 1.15 (0.80 to 1.65$)$ & .43 & $1.12(0.80$ to 1.21$)$ & .51 \\
\hline None & Ref & & Ref & \\
\hline \multicolumn{5}{|c|}{ Pelvic radiation dose, Gy } \\
\hline$<34$ & 0.85 (0.68 to 1.07$)$ & .16 & 088 (0.86 to 1.09$)$ & .28 \\
\hline$\geq 34$ & 1.35 (1.10 to 1.66$)$ & $.006 \S$ & 1.33 (1.07 to 1.65$)$ & $.008 \S$ \\
\hline None & Ref & & Ref & \\
\hline \multicolumn{5}{|c|}{ Cisplatin dose, $\mathrm{mg} / \mathrm{m}^{2}$} \\
\hline$<600$ & 0.81 (0.62 to 1.05$)$ & .11 & 0.86 (0.66 to 1.13 ) & .30 \\
\hline$\geq 600$ & 1.34 (0.95 to 1.90$)$ & .09 & 1.28 (0.91 to 1.45$)$ & .15 \\
\hline None & Ref & & Ref & \\
\hline \multicolumn{5}{|c|}{ Methotrexate } \\
\hline Yes & 0.90 (0.81 to 0.98$)$ & $.02 \S$ & 0.90 (0.80 to 1.02$)$ & $.03 \S$ \\
\hline No & Ref & & Ref & \\
\hline \multicolumn{5}{|c|}{ Amputation } \\
\hline Yes & 1.51 (0.93 to 2.44) & .09 & 1.35 (0.84 to 2.17 ) & .21 \\
\hline No & Ref & & Ref & \\
\hline \multicolumn{5}{|c|}{ Lung surgery } \\
\hline Yes & 1.75 (1.27 to 2.43 ) & $<.001 \S$ & 1.73 (1.24 to 2.39 ) & $.001 \S$ \\
\hline No & Ref & & Ref & \\
\hline
\end{tabular}

NOTE. The dead survivors were considered as frail.

Abbreviations: PRR, prevalence rate ratio; Ref, reference.

*Frailty $\geq 3$ components.

†The model was adjusted for sex, race, age at diagnosis, age at assessment, and grade 3-4 chronic conditions.

$\ddagger$ The model was adjusted for sex, race, age at diagnosis, age at assessment, grade 3-4 chronic conditions, and smoking, obesity, and sedentary behavior.

§Indicates estimates with a false discovery rate $<10 \%$. 